\title{
Modelling salmon migration as a mixture problem
}

\begin{tabular}{|c|c|}
\hline Journal: & Canadian Journal of Fisheries and Aquatic Sciences \\
\hline Manuscript ID & cjfas-2017-0546.R1 \\
\hline Manuscript Type: & Article \\
\hline $\begin{array}{r}\text { Date Submitted by the } \\
\text { Author: }\end{array}$ & 22-Jun-2018 \\
\hline Complete List of Authors: & McKinnell, Skip; N/A \\
\hline Keyword: & timing, phenology, Bonneville, Fraser, pulse \\
\hline $\begin{array}{r}\text { Is the invited manuscript } \\
\text { for consideration in a } \\
\text { Special Issue? : }\end{array}$ & Not applicable (regular submission) \\
\hline
\end{tabular}


5

\title{
Modelling salmon migration as a mixture problem
}

\author{
Skip McKinnell
}

10

2280 Brighton Ave, Victoria, BC, Canada V8S 2G2 


\section{Abstract}

Pulses of abundance in salmon migrations can arise from single populations arriving at different times, or from multiple populations with different timing characteristics, or as a combination of these. Daily

15 observations typically record an aggregate measure of abundance passing some location rather than the abundances of the individual components. An objective method is described that partitions a compound migration into its component parts by exploiting differences in the characteristics of each pulse.

Simulated data were used to demonstrate when greater model complexity may be desirable. Three case studies of increasing complexity (Chilko Lake sockeye salmon smolts, large adult Columbia River

20 chinook salmon, Fraser River salmon test fishery) demonstrate how the model can be applied in practice. Results indicated that Chilko Lake smolts rarely emigrate to sea as a single pulse, that the dates used to distinguish the Spring run of chinook salmon in the Columbia River may be overestimating its abundance, and that pulses of sockeye salmon abundance in a Fraser River ocean test fishery in 2014 may have arisen from some factor other than population composition.

Les impulsions d'abondance dans les migrations de saumon peuvent provenir de populations uniques arrivant à des moments différents, ou de populations multiples avec des caractéristiques temporelles différentes, ou comme une combinaison de celles-ci. Les observations quotidiennes enregistrent généralement une mesure globale de l'abondance passant par un endroit plutôt que l'abondance des

30 composantes individuelles. Une méthode objective est décrite qui partitionne une migration composée en ses composantes en exploitant les différences dans les caractéristiques de chaque impulsion. Des données simulées ont été utilisées pour démontrer quand une plus grande complexité du modèle peut être souhaitable. Trois études de cas de complexité croissante (saumoneaux du saumon rouge du lac Chilko, grand saumon quinnat adulte du fleuve Columbia, pêche expérimentale au saumon dans le 
35 fleuve Fraser) montrent comment le modèle peut être appliqué dans la pratique. Les résultats indiquent que les saumoneaux du lac Chilko émigrent rarement en mer en une seule impulsion, que les dates utilisées pour distinguer la migration printanière du saumon quinnat dans le fleuve Columbia surestiment son abondance, et que l'impulsion de l'abondance de 2014 du saumon rouge du fleuve Fraser dans une pêcherie océanique expérimentale peut avoir été causée par un facteur autre que la 40 composition de la population. 


\subsection{Introduction}

Maturing salmon return annually from the sea to spawn in freshwater where they themselves were hatched (Walton 1653). Geographic features along their migration routes create convergences where

45 their abundance can be observed. While there can be considerable variability in the numbers of daily migrants, the canonical seasonal pattern generally begins with the arrival of a few individuals followed by increasing numbers of migrants each day until a maximum daily abundance is attained, diminishing thereafter until the end of the migration some days or weeks later (Quinn 2005). At some locations, especially near large watersheds, this pattern can be repeated several times within a year as "pulses" of

50 abundance pass by on their way to a spawning location. A single population might migrate as a single pulse or as a sequence of pulses. Multiple populations co-migrating can also appear as a sequence of pulses if each has a different timing or population size. Combinations of these variants are possible as well but might be difficult to detect. An appreciation of which situation applies to any particular problem is desirable to have a priori. In salmon populations, typical migration patterns have been

55 described on the basis of regular surveys of spawning grounds. If there were no systematic timing differences between migrating populations, no model would detect them without auxiliary data.

Average dates of peak migration differ among populations because of the influence of various factors acting at different temporal and geographical scales. Large-scale oceanographic variation among years is associated with variable migration timing of Fraser River sockeye salmon (Blackburn

60 1987) with predictable patterns that persist for decades (McKinnell et al. 2012). On evolutionary time scales, persistent environmental changes have a capacity to exert selective pressure on migration characteristics (Quinn 2005; Hodson and Quinn 2002). Nevertheless, patterns that repeat from year to year allow the general characteristics of migrations to be captured in relatively simple models. The Gaussian curve has been used as a model of migration with as few as two parameters (Woodey 1987),

65 but more parameters are needed where there is a lack of symmetry in the seasonal increase and 
decrease of abundance (e.g. Schnute and Sibert 1983), as there is for Fraser River sockeye salmon for example (Hague and Patterson 2007). Accurate descriptions of migration timing and abundance can be needed to manage salmon populations because the parameters estimated by the model are used to determine when or if surpluses are available for harvest (Woodey 1987).

More complex models can also be needed when the abundance of passing fish is made up of several populations, often indistinguishable at the time, passing simultaneously. Some populations exhibit such consistent and identifiable patterns from year to year that these regularities are used to manage fisheries (Woodey 1987). Typically, however, the composition is unknown so meeting conservation imperatives requires the additional cost and effort of stock identification from genetic

75 composition (Ryman and Utter 1987; Beacham et al. 2004), scale pattern analysis (Clutter and Whitesel 1956), or some other means of determining composition. Nevertheless, a desirable objective of harvest management is, or should be to obtain the maximum value from the information provided by the abundances of passing fish before moving to the additional expense incurred with laboratory methods.

The date of maximum abundance has practical interest to fishery managers as it tends to occur 80 near the midpoint of a migration. A preliminary estimate of the total annual abundance can be made by simply doubling the abundance observed up to the peak date. Problems detecting it arise from year to year because timing varies from year to year. A small run arriving earlier than normal could initially be mistaken for a large run and fished too vigorously before the error is recognized and acted upon. A quantified history of the parameters of the pulse model might help to prevent this error as the initial

85 mistake might be an historically improbable combination of parameters. Therefore, having the best estimate of the shape of the timing/abundance curve is important.

A modelling framework that anticipates alternative migration behaviours (and sampling patterns) seems to be a desirable tool, regardless of the ultimate application. Where long histories of migration abundance data exist, the application of a consistent model fitting approach across all years 
90 can improve understanding of how key migration parameters are changing in response to natural and anthropogenic stressors. The present study describes a modelling framework that is able to accommodate a diversity of migration timing patterns and demonstrates its application in three case studies of well known salmon migrations: sockeye salmon (Oncorhynchus nerka) smolts emigrating from Chilko Lake, maturing chinook salmon (O. tshawytscha) passing Bonneville Dam on the

95 Columbia River, and an oceanic test fishery for Fraser River salmon located at the mouth of the Strait of Juan de Fuca at the southern end of Vancouver Island.

\subsection{Method}

The Schnute-Sibert (SS) curve (Equation 1) was developed to reconstruct the timing characteristics and

100 abundance of the migration of adult chinook salmon to the Stamp River on Vancouver Island (Schnute and Sibert 1983). It involved estimating the daily migration abundance of one population sampled at two sites under different circumstances (test fishery and escapement) with removals occurring in a commercial fishery. Because there were three data sources, each sampling a fraction of the population in a different way, the description of statistical errors was relatively complex. Had each site censused

105 the entire population, there would have been no sampling error so the run could have been described by what Schnute and Sibert called an exact curve. As that was not the situation, they imagined that the observed run timing curve was drawn from a probability distribution where the daily counts formed a multinomial distribution and the probability of a fish being observed on any particular day was determined by the parameters of the SS curve.

110 In the present study, the SS curve was the core of a pulse model framework because of its ability to reflect asymmetrical timing curves and because its parameters have intuitive interpretations. The basic equation describing cumulative abundance at time $t$ is 


$$
X_{t}=X_{\infty}\left[1-b \mathrm{e}^{\left[-x^{\prime}(1-b)^{\frac{-(1-b)}{b}} \times(t-\tau)\right]}\right]^{\frac{1}{b}} \quad \text { EQUATION } 1:
$$

where the parameters, with symbols retained from Schnute \& Sibert (1983), are:

$115 X_{\infty}$ - total run; total fishery arrivals

$b$ - skewness

$x^{\prime}$ - peak daily arrival fraction (compression)

$\tau$ - point of inflection (indicates peak date)

where the daily passing abundance is obtained by a first difference of the cumulative abundance.

\section{$\underline{2.1 \text { Pulse Model }}$}

The word pulse in this study is a transient period of abundance during a migration of one or more populations where the data provide the context for "abundance". In extreme situations, the appearance of a single fish might represent a pulse in a nearly-extirpated population but a single fish would not be

125 of much interest where 20 million individuals are expected. In the pulse migration model, abundance is the sum of $N$ cumulative run timing curves (Equation 2). For example, if a river has an early and late run, each having a single peak, then $N=2$. The basic data are typically of two types: counts of numbers of migrating fish passing some location (e.g. a fish ladder) in a fixed time interval, or counts of fish obtained by sampling the passing abundance (e.g. a test fishery). Where appropriate, the numbers

130 caught in a fishery can be adjusted to reflect the variable effort expended to make the observations, as in catch per unit of effort (CPUE).

The structure of the model is clarified with some simple mathematical notation. Let $y_{t}$ and $Y_{t}$ be the number of fish and cumulative number observed on (to) day of year (DOY) $t$. Hereafter, small letters indicate numbers while capital letters indicate cumulative numbers (or CPUE). Let $t_{s}$ be the day 
135 of year the first fish arrives and let $t_{e}$ be the day of year the last fish passes. The choice of dates is somewhat flexible but the intent is to capture the period of greatest interest including the asymptotic abundance. As their choice can affect the parameter estimates, when several analyses are being

compared, $t_{s}$ and $t_{e}$ should be common to all of the comparisons. Let $\Omega=\sum_{t_{s}}^{t_{e}} y_{t}$ be the integral number of fish observed and $z_{t}=y_{t} / \Omega$ be the proportion of fish arriving on day of year $t$. The observations $y_{t}$ are 140 assumed to follow a multinomial distribution; $\operatorname{MULT}(\Omega, z)$.

To establish the degree of complexity of the model, choose $N>0$ as some integer number of pulses of abundance. Daily total abundance across pulses $\left(r_{\mathrm{t}}\right)$ is determined by first differencing the

cumulative abundance $R_{t}=\sum_{t_{s}}^{t_{e}} Q_{t j}$ in the model where $Q_{t j}$ is the expected cumulative number of fish in the $j^{\text {th }}$ pulse up to DOY $=t$ determined according to Equation 2. Let the probability of a fish passing on

145 DOY $=t$, be $\dot{z}_{t}$ which is computed as $\dot{z}_{t}=r_{t} \div X_{\infty}$. Let $S_{j}$ be the abundance of the $j^{t h}$ pulse at the end of the migration, computed as $\pi_{j} \times X_{\infty}$ where the proportions are constrained $\left(0 \geq \pi_{j} \geq 1, \sum \pi<1\right)$. $X_{\infty}$ is often known from historical data so need not be estimated (Schnute and Sibert 1983). As cumulative run timing curves are generally asymptotic, fixing $X_{\infty}$ at $\Omega$ generally provided a satisfactory result. Shape and timing parameters for each pulse are assumed to be independent. This flexibility can be 150 reduced, for example, if all pulses are known to share a common value of $b$. Where the choice is ambiguous, $N$ should be varied and the results of various choices compared objectively using the Akaike Information Criterion (AIC, Akaike 1974). Maximum $N$ will depend to a certain extent on the duration of the migration as each pulse requires a number of days to be resolved. Too few days per pulse and the shape parameters especially will be poorly resolved with very wide confidence intervals. 
155 Overfitting can be controlled somewhat by specifying some minimum number of days $(\delta)$ between the peak dates of adjacent pulses. This was useful when a large pulse has a "shoulder" that need not be distinguished.

$$
Q_{t j}=X_{\infty} \times \pi_{j}\left[1-b_{j} \mathrm{e}^{\left[-x_{j}^{\prime}\left(1-b_{j}\right)^{\left(\frac{\left(1-b_{j}\right)}{\left.b_{j}\right)}\right.} \times\left(t-\tau_{j}\right)\right]}\right]^{\frac{1}{b_{j}}} \quad \text { EQUATION 2: }
$$

$160 \quad 2.2$ Likelihood and parameter estimation

The challenge is to find values for a vector of parameters, $\theta\left\{b_{j}, x_{j}^{\prime}, \tau_{j}, \pi^{0.5}{ }_{j}\right\}$ to bring the daily abundances in the model as close as possible to what was observed. Estimating the parameters of models of grouped data has a history in fisheries science that dates back at least to McDonald and Pitcher (1979), including Schnute and Fournier (1980), Foucher and Fournier (1982), Fournier and 165 Archibald (1982), and Fournier and Breen (1983). The degree of closeness is based on the multinomial $\log$-likelihood $(l)$ function (Rao 1965). Applied to the pulse model, the log-likelihood of $(\theta \mid y)$ is

$$
\log L=\Omega \times \sum_{t_{s}}^{t_{e}} z_{t} \log _{e}\left(\dot{z}_{t} ; \theta\right) \quad \text { EQUATION } 3:
$$

Maximizing Equation 3 is equivalent to minimizing twice the negative log-likelihood (Macdonald and 170 Pitcher 1979), hereafter designated as $\lambda$.

$$
\lambda=(-2 \Omega) \sum_{t_{s}}^{t_{e}} z_{t} \log _{e}\left(\frac{\dot{z}_{t}}{z_{t}}\right) \text { EQUATION 4: }
$$

When $z_{t}=0$, the contribution of the $t^{\text {th }}$ observation in the summation is assumed to be zero (Macdonald and Pitcher 1979, Schnute and Fournier 1980). Citing Rao (1965), Macdonald and Pitcher (1979) 
pointed out that the maximum likelihood estimates (MLE) and the statistics derived from them are the

175 same as those found using $\chi^{2}$ or modified $\chi^{2}$ when sample sizes are large, as they generally are in fish migrations. Having alternative objective functions that generate MLE proved useful in practical application because the function minimizer was occasionally challenged by the topography of $\lambda$.

Schnute and Fournier (1980) found that numerical stability could be achieved by minimizing a separation statistic $A$ which also produces MLE at its minimum (Equation 5). $A$ is increasingly positive

180 when observed and model frequencies diverge and $A=0$ when they are identical. This was used as the objective function in the present study. Once a minimum value of $A$ had been found, it is possible to compute $\lambda$ and the AIC.

$$
A=2 \sum_{t_{s}}^{t_{e}} y_{t} \log _{e}\left(\frac{r_{t}}{y_{t}}\right){ }_{\text {EQUATION } 5:}
$$

185 As the sum of proportions in all pulses must equal one, only $N-1$ proportions $\left(\pi_{j}\right)$ are estimated and the $N^{\text {th }}$ is obtained by subtraction. AIC $=\lambda+2 \mathrm{~K}$ where $\mathrm{K}$ is the number of variable parameters to be estimated, or 4N - the number of fixed parameters (Burnham and Anderson 2001).

The Mittertreiner and Schnute (1985) implementation of the Nelder-Mead algorithm was used to obtain the estimates of the parameters, their standard errors, and from these the approximate $95 \%$

190 confidence intervals. All searches began by initially holding values of well-determined parameters (e.g. the approximate peak date of a prominent peak) fixed at values that were known to be near the solution. After reaching a solution to the constrained search, these parameters were allowed to vary. Constraints on the parameter space were needed because the simplex algorithm can, especially with a poorly resolved pulse, take model parameters (or intermediate calculations) to extreme values, including some 195 that cannot be represented on a digital computer. The parameter $b$ for example must be $<1.0$ and was 
constrained arbitrarily to exceed -9.0. Only once in the present study was a final solution found with $b$ at this constraint. The compression parameter, $x^{\prime}$, must lie between 0.0 and 1.0. Peak dates were constrained to lie within the bounds of the first and last days of observation. The proportions $\left(\pi_{j}\right)$ were parameterized as $\pi_{\mathrm{j}}^{0.5}$ and constrained to be $\geq 0$. If any parameter tended toward an unreasonable value

200 during a search, a penalty was added to $A$ to retain the search within the constrained parameter space. Good initial estimates reduce the chance of converging on a local rather than a global minimum in the objective function. A practical approach to fitting this model to the data is described the Appendix. Some of the issues and challenges of fitting the models to data were examined in a simple simulation and three case studies.

205

\section{$\underline{2.3 \text { Evidence of complexity }}$}

When pulses of migration occur they can often be readily evident in graphical representations of the data. When there is ambiguity, perhaps due to a dominance of high frequency variability, one of the first decisions to be made in modelling a migration is whether the greater complexity of a pulse model

210 is required. Some characteristic patterns are exhibited when model complexity is insufficient. A simple example shows how a lack of complexity can be detected. Imagine three co-migrating populations passing through a fish ladder with an observer counting the total daily abundances. For simplicity, each of the three populations has identical shape parameters $\left(b=-1.0\right.$ and $\left.x^{\prime}=0.05\right)$ with the abundance of each of the two earliest populations set at 1000 individuals, while the third was 2000 individuals. Only

215 the peak dates of migration differ among populations $\left(\tau_{j=1 . .3}=110,180,250\right)$, which are approximately the long-term peak migration dates of the chinook salmon runs at Bonneville dam which will be the focus of Case Study 2. With these parameters, simulated fish began to appear on March 15 (day 76) and the observer stopped tallying on November 16 (day 320). No sampling errors were introduced in the simulated data as the objective here was to demonstrate when a pulse model might be desirable. 


\subsection{Case studies}

Three case studies demonstrate how the pulse model framework can be applied in practice. The first is the relatively simple case of sockeye salmon smolts emigrating from Chilko Lake (Fraser River watershed) in multiple pulses. Counts of migrants at this location form a part of the primary index of

225 postsmolt-to-adult survival in the Fraser River (Akenhead et al. 2016). The second case study uses the pulse model to describe the annual upstream migrations of three "runs" (sensu Mason 1965) of adult chinook salmon past Bonneville, the terminal dam on the Columbia River, over a 38 year period from 1980 to 2017. Abundances of each run are compared with traditional estimates of their abundance (based on fixed dates of migration) that were established in the late 1930s. A third case study

230 demonstrates the application of the pulse model to an oceanic migration of sockeye salmon through a test fishery in the Strait of Juan de Fuca (separating Washington State from Vancouver Island) where the data collected are relative abundance rather than absolute abundance, as daily catch per unit effort (CPUE) using two different gear types with a period of overlap. At this site, DNA was used to identify the composition of passing populations and these data were compared with the pulses of abundance.

\subsection{Results}

\section{$\underline{3.1 \text { Under- and over-fitting }}$}

When the simulated data with three pulses were fit to a model with a single pulse, the estimate of a

240 single peak date (DOY 248.7 \pm 0.6 ) was closer to the known date of the largest pulse (DOY 250) than to the dates of the smaller early pulses (DOY 110 and 180) (Table 1). This occurred because the greatest reductions in the objective function were a result of fitting the model to the largest anomalies. Visual inspection of the residuals (observed-modelled) was sufficient to identify the lack of fit $\left(\mathrm{R}^{2}=25 \%\right)$ of a 
single pulse model to these data (Figure 1). Furthermore, the residuals had a characteristic

245 autocorrelation pattern that appears often when the number of pulses of a migration was

underestimated. Tracing the lack of fit through the migration, the abundance was overestimated by the model in the earliest part of the migration. As the days passed, an "unexpected" abundance of fish appeared due to the arrival of the earliest migrating population. This caused the residuals to lessen in magnitude, approaching zero. The abundance was "unexpected" because the model had only a single

250 pulse of migration, and not one occurring near the beginning of the run. When the second population arrived, the residuals returned to negative as the model predicted more fish than was observed. This pattern of alternating phases of high and low (often positive and negative) residuals repeated as additional pulses of fish passed by (Figure 1). The number of inflections can potentially provide a hint at how many pulses are required to adequately fit the observed data.

When a model allowing two pulses was fit to these data, a better fit $\left(\mathrm{R}^{2}=70 \%\right)$ with a lower AIC was the result (Figure 1) because the large late pulse was distinguished from the two earlier smaller pulses (Table 1). The autocorrelated residuals that remained suggested a need for even greater complexity. When set to three pulses, the parameter values that were used to created the simulated run were recovered to within a few decimal points. Fitting the data to a four pulse model resulted in three

260 well determined peaks in the expected proportions and one peak with $\pi_{\mathrm{j}}=0$ and a higher AIC (Table 1).

Some readers may be concerned that the parameter estimates (Table 1), when a three pulse model was fit to data known to have three pulses, were not exactly those used initially to create the simulated data. These relatively small differences arose because the simulation created integer numbers of fish from an equation that produced decimal fractions of fish. So the expected numbers of fish on

265 any day can never match exactly the observed numbers of fish. Nevertheless, the simulation has shown substantial reductions in AIC with increasing complexity and that overfitting did not go undetected in this simple problem. When the expected results are not known, overfitting may become an issue as 
complexity is increased. This topic is dealt with later, after an examination of case study results that apply the model to historical data. The first case study demonstrates how complexity can vary among 270 years within one system.

\subsection{Case 1: Chilko Lake sockeye salmon smolt run}

Since the 1950s, the abundance of sockeye salmon smolts emigrating from Chilko Lake (Fraser River watershed) has been recorded at a counting fence located in the Chilko River below the outlet of the

275 lake (Roos 1985). Smolts are guided by the design of the fence toward convergences where white boards are attached to the bottom of the river. Still cameras located above take photographs at frequent intervals as they swim over. Estimates of the daily abundance of one and two year old smolts (age composition is determined by daily samples of the smolts) are developed from the photographs, currently done by Fisheries and Oceans Canada. As two year old smolts account for only about 5\% of

280 the annual total number of emigrants (Akenhead et al. 2016), the data used in this case study were total daily abundances. For demonstrative purposes, migrations occurring from 1998 to 2001 were selected for analysis as these years exhibited both differences and similarities among years that the model was able to detect (Figure 2).

High frequency variability was reduced by applying a three day running mean to the daily

285 numbers of smolts. Expected total abundance in the model $\left(X_{\infty}\right)$ was fixed at $\Omega$ in each year. As the entire migration occurs over a period of approximately one month, a narrow sliding window (3 days) was used in the initial search for tentative pulses (details in the Appendix). A narrow window will typically generate more pulses initially than a broad window. The minimum span between pulses was fixed $\delta=5$ days. Shorter spans result in poorly determined shape parameters. A search of the 1998 data,

290 for example, found candidate peaks at DOY =115, 127 and 136, which was very close to the model fit (Table 2). Their good correspondence with the initial estimates and the relatively narrow confidence 
intervals produced by the model were because the smolt migration in 1998 had very well determined peaks and little high frequency variation in the abundance time series (Figure 2). The last pulse was symmetrical whereas the second (largest) pulse had a greater proportion of the pulse emigrating prior to

295 the peak. Skewness of the first peak was intermediate between the first and last pulse. All pulses exhibited very compressed emigrations with high proportions of the pulses leaving on the peak dates (Table 2). The migration in 1999 lacked the prominent early peak that occurred in 1998 and was best fit by a single pulse model, whereas the migration of 2000 was fit best by two pulses as was the migration in 2001 (Table 2, Figure 2). The latter featured a large initial pulse that included a few days of slightly

300 lower abundance near the peak, followed by a smaller later pulse. From 1999 to 2001, there was some evidence of "shoulder" peaks or ephemeral spikes of abundance but setting $\delta \geq 5$ kept them from being distinguished from the greater abundance of an adjacent pulse. From 1998 to 2001, the coefficients of determination were: $99 \%, 94 \%, 80 \%$, and $95 \%$, respectively. Further examination of the entire history of these smolt migration data from the 1950s may provide some guidance about which pulses have

305 appeared systematically throughout history.

An important result of this case study was finding that a single pulse of migration was not the best model of the smolt emigration from Chilko Lake in three of four years. Whether these pulses of smolts remained independent on their migration to the sea is not known with certainty, but given that the migration distance to the sea is about seven days (Clark et al. 2016), which is approximately the

310 time elapsed between adjacent peaks, it seems likely that distinct pulses of smolts arrived at the Fraser River estuary on different dates. While the model will not immediately determine what has caused a migration to leave Chilko Lake in pulses, the parameters describing each pulse, its shape and timing, and the numbers of pulses, may provide clues to the cause if studied for a sufficient number of years.

\section{3.3 Case 2: Chinook salmon: Bonneville Dam}


This case study applied the model to 38 years of daily counts of large adult chinook salmon spawners at the terminal dam (Bonneville) on the Columbia River mainstem. Counting began in 1938, traditionally from March 15 to November 15, but it was not until 1980 that older, larger chinook adults were counted separately from younger, smaller chinook salmon adults $(<56 \mathrm{~cm})$. As the two size groups

320 differ somewhat in their timing, the analysis was restricted to the larger adults to avoid biases that would arise from having variable fractions of large and small adults in the run from year to year. Then, as now, the run of chinook salmon past Bonneville has three major stages of abundance: a Spring run with a peak after the spring equinox, followed by a Summer run of relatively low but continuous migration, followed by a large Fall run (Figure 3). The date of the start of the Fall run at Bonneville

325 (August 1) was established initially on the basis of the 1938 run, the first year of operation of the ladder (Rich 1942). The beginning of the Summer run was May 29 then but is now June 1 (and since 2005 it is June 15 for fishery management purposes). Counting migrants within these fixed dates provides a firstorder approximation of the abundance of each run, but the pulse model suggests that they may not reflect the abundance of the runs in the $21^{\text {st }}$ century because timing has changed.

The application of fixed calendar dates to determine the relative abundances of runs is sensible if there are small year to year differences in timing, and/or the timing of runs are so distinct that misallocation of a few fish will not seriously affect the estimates of abundance (Beer 2007). On the other hand, if timing varies significantly from year to year and if the runs should overlap, as seems to have occurred in some years, there is a potential for error. Anderson and Beer (2009) recognized this

335 problem and addressed it by determining the timing of each run from the data using something akin to a mixture of normals model (Hasselblad 1966). The parameters estimated for each run included the mean date and its standard deviation. The result was a more satisfactory assessment of the relative abundances and timing of each run than was possible with fixed dates established arbitrarily. A shortcoming of a mixture of normals model is that the run components are assumed to be symmetrical, 
340 and the results presented here suggest that they are not. While other approaches exist (e.g. Bonner and Schwarz 2011), the pulse model includes a skewness parameter that allows an assumption of symmetry to be tested explicitly.

Generally since 1980 a three pulse model was a good description of the migration shape, abundance, and timing with high coefficients of determination each year (median 93\%). The minimum

345 (77\%) occurred in 2017 when the Spring run arrived as two distinct pulses rather than one. In some years both the Spring and Fall runs had evidence of more than one pulse but the peaks were sufficiently close that modelling the passing abundance as a single peak was a good approximation. When trying to describe the migrations in these types of years, an alternative approach is to increase the number of pulses allowed, find the most parsimonious fit, then identify which pulse belongs to which run.

350 Considering the relatively poor fit of a three pulse model to the 2017 data, alternative models with greater numbers of pulses were tried and the results are discussed below.

While they were few in number, the years 1987, 1988, 1993, 1997 and 2001 were particularly difficult to fit to a three pulse model because of a weak (or no) distinguishable Summer peak and/or because either of the larger Spring or Fall runs arrived as two distinguishable pulses rather than a single

355 pulse. The objective function was reduced more by fitting a shoulder or second peak in the Spring or Fall runs than by fitting a weakly defined Summer peak. A workable solution to this problem was to fix the peak date of the Summer run in the model at the observed peak day of year, if it could be distinguished, letting the remaining parameters to vary freely. Where a Summer peak was not evident the long-term mean was used. Viewing the time series as a log-transform was sometimes useful for

360 finding an initial peak date for the Summer run because this transformation expands the variability at lower abundance and reduces it at higher abundance. After finding a suitable date, the model was fit to the untransformed data.

The distributions of annually estimated parameter values provide some insight into the basic 
characteristics of runs (Table 3). The peak date of the Fall run has consistently narrow confidence

365 intervals while the peak date of the Summer run has had the broadest interval estimates (Figure 4). The Summer run peak dates became more precise beginning in 2001, primarily because the period of peak abundance became more prominent. Peak dates for the Spring run are relatively well determined in most years and they also became more precise after the millennium. The trend to later peak dates in the Spring run (linear regression, $\mathrm{P}<0.01)$ was a result of a relatively abrupt change in timing $(\sim 6$ days

370 later) after the millennium rather than a constant rate of change. This change was accompanied by a more compressed migration (average: $x^{\prime}=0.034$ before 2001, $x^{\prime}=0.055$ after; ANOVA $[\mathrm{P}<0.01]$ ). The Summer run has a linear trend to earlier peaks (Figure 4) but there is no linear trend in the peak date of Fall run. Low correlations of peak dates among the runs indicate that annual timing anomalies of each run are independent. Considering the greater abundance and multi-racial composition of the Fall run

375 (Van Hyning 1968), it is remarkable that it has had such low interannual variation. Perhaps there are fewer factors (or less exposure to them) affecting oceanic migrations in this run or a stronger response to in-river conditions.

While there were years when an hypothesis of symmetry could not be rejected, these were very much in a minority (Figure 5). For most years, the lower bound of the interval estimates for $b$ exceeded $380-1$ indicating that each run has a more rapid rise to the peak date than decline from it, rather than a symmetrical increase and decrease in abundance. Only the Fall run and only in 1988 was the value of $b$ determined by an arbitrary constraint ( $b$ constrained to values $\geq-9$ ). This occurred because an early shoulder peak was well separated from the main Fall peak which increased the skewness. The proportion of the Spring run in the total return to Bonneville has declined (linear regression, $\mathrm{P}<0.05$ )

385 and the proportion of Summer run is larger now (linear regression, $\mathrm{P}<0.05$ ) than formerly. The change in the Summer run fraction seems more like an abrupt increase in the mean state beginning in the new millennium rather than a linear trend as low proportions $(\sim 0.1)$ have become much less frequent and 
high proportions $(\sim 0.2)$ are more frequent (Figure 4).

The average discrepancies in abundance (fixed date minus model) between the two methods

390 prior to the new millennium were relatively small $(<\sim 5 \%)$ for the Spring and Fall runs but relatively large $(30 \%)$ for the Summer run (Table 4). Compared to the model, traditional dates generally placed more fish in the Spring and Fall runs and fewer in the Summer run than the model. The fishery management transition date (June 15) exaggerates that pattern even more. After 2000 this difference was enhanced further (Figure 6). Some of the increase in the magnitude of the discrepancies was due to

395 a general increase in abundance but the pattern of variability suggests that there is more going on than a change in abundance. Natural and non-natural causes should be explored.

The pulse model results as well as the general shapes of the migrations seen in the long-term average pattern (Figure 3) suggest that May 31 was a reasonable choice for the end of the Spring run, but the shape of the Summer run with low compression, $x^{\prime}$, suggests that May 31 was too late to begin

400 counting the Summer run. There is a suggestion that there may be a period of overlap in the Spring to Summer transition caused mostly by the general shape of the Summer run. If true, a simple division of runs at May 31 would lead to Summer run fish subsidizing the Spring run abundance. Arbitrary transition dates later than May 31 will simply exaggerate this difference. In all years examined, traditional Fall run counts were greater than model allocations (Figure 6). As with the Spring-Summer

405 transition, the broadly timed Summer run intersects with the highly compressed Fall run. The results of the model suggest that some Summer run fish are counted as part of the Fall run. Considering the relative magnitude of the Fall run, August 1 was probably not an unreasonable date to start counting the Fall run but it may be too early top stop counting the smaller Summer run. The relative effect will be greater on the latter.

The Spring run of 2017 arrived in two peaks (Figure 7) giving rise to the worst fit of any year to a three pulse model. The constraint of fitting three pulses to the data was removed to determine how 
models of greater or even lesser complexity might fair. The search for initial estimates used a sliding quadratic window of 7 days, a small minimum fraction for a pulse $(0.5 \%)$, and $\delta=7$. A total of 10 qualifying pulses was found. After fitting this model, the number of pulses was reduced and the model

415 was fit in the reduced parameter space. The pulse to omit on each iteration was determined primarily by selecting weakly determined pulses first (e.g. peak dates $<2$ days apart). If none were found, the smallest pulse was omitted. The lowest AIC was found at $\mathrm{N}=5$ pulses (Table 5). The first two pulses (both $6.1 \%$ ) occurred during the normal time of the Spring run, the second (23.8\%) was the Summer run and the last two $(34.4 \%$ and $29.6 \%)$ formed the traditional Fall run group. The proportions

420 estimated by forcing a three pulse solution on the 2017 data were Spring: $23 \%$, Summer: $12.8 \%$, and Fall: $64.2 \%$. The allocation to the Fall run differed by only $0.1 \%$ between the two models, but the three pulse solution has allocated $10.8 \%$ more to the Spring run (and less to the Summer run) than a five pulse solution. But there is no way of knowing, by either method of allocation, whether the peak on DOY 142 was truly a delayed second Spring run peak or an extremely early first Summer run peak. Without independent confirmation there is a risk of over-interpreting the results of allocations to runs made either by the pulse model or by traditional counts. Both methods rely on the shapes of the run timing curves to allocate fish to runs. The major issue is to understand the transitions. Fixed dates do not acknowledge that runs may have a period of overlap during transition, or if it is acknowledged, it must assume that equal and offsetting numbers of fish are misclassified. Genetic differences

430 measured in the periods of transition should make it possible to understand which model (fixed dates or pulse model) is providing more accurate counts for stock assessment and forecasting. One genetic stock identification study at Bonneville Dam in 2005 found Summer run fish arriving before June 1 in that year with considerable numbers of Summer run fish arriving by June 15 (Narum et al. 2007). They also found that the likelihood of a fish being from the Spring run declined markedly prior to June 1 in 2005. 435 What the pulse model was not able to capture that was found during the 2005 study was the high 
likelihood of Fall run fish passing throughout the Summer period and to a lesser extent even during the end of the Spring run. The primary reason for having the best allocations of fish to runs is that it affects measures of annual productivity. Misclassification makes runs appear more or less productive and as harvest rates are often based on productivity, getting the best estimates of abundance seems desirable.

440 The risk associated with using fixed dates to determine the magnitude of a run is that run timing is not fixed. Fortunately, the Columbia River system has many stock assessment assets to bring to bear on this issue.

\subsection{Case 3: Juan de Fuca Strait test fishery}

445 The migrations of sockeye salmon and pink salmon (O. gorbuscha) through the approach routes to the Fraser River are monitored annually by the Pacific Salmon Commission using gillnet and seine test fisheries (McKinnell et al. 1999). Pulses of abundance detected in these fisheries are thought to arise primarily from variable abundance rather than variable catchability. Boats with gillnets are deployed in late June or early July when the abundances of salmon tend to be lower. These are replaced by boats

450 equipped with seine nets when the abundances of larger populations begin arriving in mid-July. The period of overlap between the two gear types varies among years. In recent years, tissue samples have been obtained from the test fishery catch to assess the composition of populations using genetic stock identification techniques (Beacham et al. 2004). The spawning migration of sockeye salmon in 2014 was selected for study because of: 1) a relatively large return, 2) a lengthy period of overlap when both

455 the gillnet and seine test fisheries were operating allowing all of the components expected in the return to be observed, and 3) there was regular sampling of the test fishery catch for DNA. Although the composition of the catch is determined at the population level, the proportions within samples were aggregated as six "regional stocks" or "timing groups" that are often used to manage fisheries: Early Stuart, Early Summer, Summer, Birkenhead, Late, and nonFraser. The latter is dominated by fish 
460 migrating to rivers in Washington State (Baker R. and L. Washington) in the earliest part of the season. In 2014, the gillnet test fishery operated from DOY 171 (June 20) to DOY 227 (August 15) and the seine test fishery operated between DOY 206 (July 26) and DOY 245 (September 2). The daily catches are transformed to gear-specific time series of CPUE. On a day when no fishing occurred, CPUE for that day was interpolated from adjacent days. DNA sampling of the catch was frequent but

465 not always daily. For example, the first of 14 DNA samples of the gillnet test fishery catch was collected during the period between June 25 and June 28 but the second sampling occurred only on July 5. Thereafter sampling became more frequent. Eleven DNA samples were obtained from catches in the seine test fishery. Only one day (August 1) featured samples collected from both test fisheries on the same day (the gillnet sample was a composite from July 31 to August 2) so an average proportion

470 of the two gear types was used as the stock composition for August 1. The proportions were similar in both gear types. Because the test fisheries sampled different but overlapping periods, the pulse model was fit separately to the CPUE data from each test fishery. Within each gear type, the number of pulses in the model resulting in the lowest AIC was selected as the most parsimonious model of the run. The DNA data were not used to estimate parameters of the timing model, but once a pulse had been

475 identified, the DNA provided information on what populations were responsible for the pulse.

The sockeye salmon passing through the entrance to the Strait of Juan de Fuca in 2014 occurred as a series of seven pulses (Figure 8). Six of the pulses were found in the gillnet test fishery and three in the seine test fishery. The sequential order of regional stock abundances in 2014, determined by DNA, followed the expected pattern (Woodey 1987). Peak dates of abundance, however, did not correspond

480 with the peak dates in proportions of any regional stocks (Figure 8). Pulses of abundance generally consisted of high proportions of at least two regional stocks. This pattern suggests that the factors responsible for creating pulses of abundance are different from those responsible for organizing composition of the stocks in each pulse. As they approach freshwater even social interactions among 
fishes may working to structure migrations (Berdahl et al. 2017).

for these pulses (fifth and sixth) were not significantly different based on overlapping 95\% confidence intervals (Table 6). Peak dates estimated from the seine test fishery data had narrower confidence intervals ( $\sim 1$ day) than those of the gillnet test fishery ( $\sim 1$ week). Estimates of skewness of pulses differed more both within and between gear types, with some pulses having a rapid rise to a peak and

490 others having a slower rise to the peak and a more rapid decline (Table 6). Some of the differences between gear types may have arisen from partial sampling of pulses. The seine test fishery did not begin early enough to capture the beginning of the fifth pulse so that pulse began with an abundance of fish leading to a higher value of $b$ than was found in the gillnet test fishery data (Table 6). This pulse also featured a relatively poor fit to the observations (Figure 8), but the sixth and seventh pulses had 495 relatively better fits. Uncertainty about skewness was generally higher in the gillnet test fishery because of the ephemeral nature of some pulses (Table 6). For example, if a peak of only one day occurs in a pulse lasting only five days, the parameters describing the shape of the curve can never be well determined. Reducing the complexity of the model is suggested in these situations, perhaps by establishing a shared $b$ parameter for short pulses. Parameter estimates from the two gear types had

500 better agreement when sampling captured most of a pulse, as was the case for the sixth pulse.

Compression parameters ranged from 0.08 to 0.35 among all pulses and gear types (Table 6). In the fifth pulse, which was relatively well sampled by both gear types, the difference in compression between gear types was 0.1 which seems rather high (Table 6) but this difference may have been due to the seine test fishery starting too late in that pulse. The fit is better in the gillnet data which sampled the 505 pulse completely (Figure 8). The largest pulses observed by the gillnet test fishery were the third ( DOY 189, primarily Washington State and early arriving Canadian populations) and fourth ( DOY 198, predominately Summer and Early Summer). The latter was more compressed $\left(x^{\prime}=0.23\right)$ than the 
broader third pulse $\left(x^{\prime}=0.12\right)$. The fifth and seventh peak were the largest $(37 \%)$ sampled by the seine test fishery but the fourth pulse was nearly as large (32\%) despite having a much lower abundance on

510 the peak date. Had the beginning of the fourth pulse been fully sampled by the seine test fishery, it is likely that the proportion of fish allocated to this pulse would have been lower.

\section{Discussion}

A simple model with a single peak and symmetry can be used where the details of a migration are of no

515 consequence. Climate change analysts do this routinely by fitting simple linear regressions to time series of data that may or often do not not have an underlying linear property. The long-term slope is what is reported because it is easy to communicate. Oversimplifying the complexity of physical and biological systems, however, can potentially hamper efforts to understand the causes of variability in nature. The concept behind Einstein's idea of "but no simpler" has not yet been applied in migration

520 models in part because there are so few that attempt to capture greater complexity. In the present study, the simplest migration model, a single pulse, was rarely the best description. Well-sampled migrations that take several weeks to exhibit the canonical form generally lead to narrow confidence intervals. Case Study 3 made it clear that there are limits to what can be discovered from some time series. The peak date of a strong pulse lasting for a week or more will be associated with relatively narrow

525 confidence intervals compared to those parameters responsible for describing pulse shape which cannot be determined from an ephemeral abundance lasting only a few days. Generally, one might expect that as the ratio of the migration duration to the number of pulses decreases, the uncertainty about the shape of pulses increases. Case Study 2 involved three pulses and a migration lasting several months so the shape parameters will be better determined than in Case Study 1, for example, where the migration was

530 finished in one month.

Recognizing that multiple pulses are occurring year after year in a migration may lead to new 
insights about a migration. A repeated appearance of two or more pulses in a population can easily lead to hypotheses that these pulses have biological causes rather than random effects or environmental variability. Certainly, DNA stock identification techniques have developed to a point where it may be

535 possible to test a null hypothesis of no difference in genetic makeup between pulses. Pulses may also arise if there are different average ages and/or sizes of fish in each pulse.

As the present pulse model framework is an unsupervised mixture problem, care must be taken to understand what parameters can be resolved with any certainty using this technique. The results of this study suggest that pulses of abundance that were readily seen in graphical representations of the

540 data generally had narrow confidence intervals. Practical applications of the model in future should generally be preceded by simulation experiments that test how well the model recovers parameters in more difficult situations. These problems will vary from location to location but the greatest difficulties will likely arise from poorly determined peaks where the parameters describing one run are very similar to those describing another. Difficulties will also arise in situations where the total abundance is

545 low as this tends to exaggerate high frequency variability. If the pulses in some migration are not of the canonical form described in the introduction, a pulse model framework is not likely to be of much benefit. But there should be some benefit to applying the model where it is more appropriate. Two pulses of migratory smolts separated in time by two or three weeks will not likely experience the same state of nature in the ocean upon their arrival there. Indeed, there is no a priori reason to expect that 550 each pulse of migration in a year will experience the same survival if the two enter the sea at different dates. Yet, by applying only a single date (e.g. median DOY), to describe a complex migration, the state of the ocean on that date may bear little resemblance to the state of the ocean when pulses arriving earlier or later got to the sea.

In the Chilko Lake case study, all four years exhibited evidence of more than one pulse of 555 migration. In each year, multiple pulses provided better statistical descriptions of the migration than 
single pulses. Whether each pulse meets the same fate is a yet to be explored idea. Some of the pulses, such as that found in 1999, may not be biologically significant but learning that they exist will potentially direct some intellectual effort toward a better understanding. No doubt that at least some of the improved fits to the data arising from greater model complexity are simply a consequence of the 560 greater flexibility offered by entertaining more parameters in the model. Fortunately, there are tools, such as the AIC to suggest whether value was added by increasing model complexity, and helps to keep overfitting in check. If only minor improvements in fit were obtained by considering a two pulse model over a single pulse, additional complexity in the model is probably not warranted. On the other hand, where multiple pulses are known to occur, the model can easily be expanded to accommodate 565 them. One technical consequence of increasing model complexity is that it increases the number of parameters to be estimated. In theory, this is not a major issue but in practice, model fitting becomes more difficult as the dimensionality of a problem increases. The classical problem in nonlinear parameter estimation of having multiple minima in the objective function leaves a possibility of finding several potential solutions. However, in the pulse model framework some control over parameter

570 expansion is possible by invoking simplifying assumptions where warranted, as in the following example.

Both the single pulse model (Equation 1) and the multi-pulse model (Equation 2) can be adapted to situations where a pulse of migrants is observed multiple times at a sequence of locations. The original SS model was an expansion of a single pulse model to two locations. Some migrations, 575 such as those in the Columbia River, are observed multiple times in sequence with multiple pulses seen at each. Indeed, a recipe for parameter explosion if the whole system is described in one model. Predicting the numbers of migrants at each location may require simplifying assumptions about the parameters at each location. One extreme simplification that is likely unrealistic, is that the abundance and shape parameters are the same at each dam. In this case, only the peak date parameter needs to be 
580 estimated as it cannot be a constant at all dams. However, expected peak dates at multiple dams could be simplified to a linear function of the distance (or perhaps elevation) from the first point of observation as $\tau=\tau_{1}+v \times D_{k}$ EQUATION $6:$

where peak migration date at the $\mathrm{k}^{\text {th }}$ location is estimated as a linear function of the peak date at the first 585 location $\left(\tau_{1}\right)$, a constant migration speed $(v)$, and the distance to the $\mathrm{k}^{\text {th }}$ location from the first location $\left(D_{k}\right)$. Slightly greater complexity would be needed in this example if the rate of migration is expected to change systematically with distance. A simple expansion of Equation 6 (adding a quadratic term) allows for migration speed to vary as a quadratic function of distance rather than a linear function of distance. For salmonids, migration speed could also be characterized as a function of elevation rather

590 than distance. Modifying the model in this way adds a third parameter, $v_{l}$, that will allow migration speed to increase $\left(v_{1}>0\right)$ or decrease $\left(v_{1}<0\right)$ to reflect what occurs in the data. Even more complex parameterizations are possible, but the key point in this approach is that peak migration dates at all locations can be captured in as few as two parameters. The same approach could be applied to the shape parameters if they vary with distance. For example, one could test whether a migration becomes

595 more protracted with increasing distance travelled. The null hypothesis for the test is that $x^{\prime}$ is constant. If the addition of a linear term becomes non-zero and improves the fit significantly, the null hypothesis can be rejected. The choice of what and how to re-parameterize the model will depend upon the nature of the system under study.

Fitting a three pulse model to the Columbia River large chinook migration required some 600 additional tuning for some years when the Summer run formed a very small proportion of the total migration. The difficulty arose from forcing a three pulse solution on a time series with more than three pulses. When the Summer run was at extremely low abundance, far greater reductions of the objective 
function were achieved by fitting the Summer run pulse to a "shoulder peaks" if one existed at the tail of the Spring run but especially, because of its much greater abundance, a shoulder peak of early

605 arrivals of the Fall run. Because the Summer run has been observed for many years, the history of parameter values for that run can provide a joint distribution that informs the annually fitted parameters when the data for any one year will not provide a precise estimate. Where this becomes an important problem, new research into a suitable solution will be worthwhile. In the meantime, for four years it was necessary to fix the peak date of the Summer run at the long-term average and this proved to be a

610 suitable compromise. Another less desirable workaround for this problem was to log transform the daily counts of fish in these years. This had the effect of enhancing a small Summer run peak, if there was one, and diminishing the relative size of the adjacent larger peaks. If the peak of the Summer run was apparent in plots of log-transformed abundance, the minimizer was usually able to converge to a solution. Unfortunately, the shape parameters determined by fitting the transformed data are not

615 comparable to those fit to untransformed data but the peak dates are relatively stable. Refitting the untransformed data using the peak date of the Summer run estimated from the transformed data provided a meaningful solution. Fortunately, the years with this additional challenge were few in number.

One new challenge that arises from discovering that a population exhibits more than one pulse 620 of migration is in developing the annual estimate of run timing. A simple example highlights the problem. Suppose that a smolt migration is made up of two compressed pulses of equal magnitude, separated in time by three weeks. An annual median or mean date for the entire migration is midway between the peaks, a time when few smolts are migrating. If the two peaks were separated by three weeks every year, then the median in this example can be an index of annual timing. However, if the

625 two peaks are not consistently three weeks apart, or if the fractions in each pulse vary from year to year, the median will not necessarily reflect the nature of the run. Imagine that the peak date of the 
larger of two pulses is invariant and the timing of the smaller pulse varies markedly from year to year, in response to stream flow for example. This variability would likely go undetected in an annual statistic. Generally, the challenge is to understand a biological system well enough that good choices 630 about the structure of a model are made.

Fish counting sites are frequently located landward of marine fisheries so any timing/abundance curves fit to the data obtained at these sites will be influence by the pattern of removals as well as the natural timing/abundance signal. It is a common practice in fisheries management to reconstruct the migration by adding the catch to the observed escapement. Techniques may vary depending upon the

635 nature of the fishery. Purse seine fisheries can remove large chunks of migrations over short periods of time whereas troll fisheries might remove smaller fractions of a run over an extended period. Reconstructions typically require a migration timing model so a more accurate representation of a migration should, in principle, lead to a more accurate run reconstruction.

Finally, the pulse model framework seems to be sufficiently flexible that it can be applied to 640 other phenomena that exhibit ogives. It might be of interest, for example, to capture the characteristics of significant pulses of flow in a river (freshette or autumnal rains), or to model the winter accumulation of snow. Individual salmon growth is recorded in the cumulative spacing of circuli outward from the focus of a scale. The pulses of wider spacing between circuli are annual periods of higher growth (Gilbert 1913) so there may be a potential to detect age by detecting pulses. The growth

645 exhibited by tree rings also comes to mind. A plankton bloom in the ocean might be monitored as a cumulative amount of chlorophyll observed by ocean colour sensing satellites. Some relatively minor adjustments to the fitting procedure may be needed in some cases because the cumulative curve is not constant initially as it is with salmon timing data. Workarounds for other types of data are possible, e.g. by accumulating only positive changes with time, or by starting a time series only after some threshold 650 value has been achieved. Nevertheless, the general application of the pulse model framework is 
possible and should lead to better understanding of the causes of biological and physical variability often seen in nature.

\section{Acknowledgements}

655 Keri Benner, Tracy Cone (Fisheries \& Oceans Canada) for providing and assisting with interpretation of sockeye salmon smolt counts at Chilko Lake. Pacific Salmon Commission for providing daily catch and effort of species caught in their test fisheries via its website (www.psc.org). John Candy and Andres Araujo (Molecular Genetics Laboratory, Pacific Biological Station, Fisheries \& Oceans Canada) for providing the DNA stock identification results to the Pacific Salmon Commission for their

6602014 gillnet and seine test fisheries in the Strait of Juan de Fuca. Steve Latham (Pacific Salmon Commission) for reading and offering helpful comments on a draft manuscript. The Fish Passage Center (www.fpc.org) for serving the daily counts of species passing Bonneville dam. Two anonymous referees stimulated a more thorough examination of the statistical properties of the model and were generally helpful and constructive throughout. In hindsight, I am grateful to Jon Schnute and David

665 Fournier for sharing some intellectual time and space in the early 1980s. I could not have taken this on had I not been inspired by their approach to fisheries problems.

\section{References}

Akaike, H. 1974. A new look at the statistical model identification. IEEE Transactions on Automatic

670 Control 19: 716-723. doi:10.1109/TAC.1974.1100705.

Akenhead, S.A., Irvine, J.R., Hyatt, K.D., Johnson, S.C., Michielsens, C.G.J., Grant, S.C.H. 2016. Habitat manipulations confound the interpretation of sockeye salmon recruitment patterns at Chilko Lake, British Columbia. N. Pac. Anadr. Fish Comm. Bull. 6: 391-414. doi:10.23849/npafcb6/391.414. 
675

Anderson, J.J., Beer, W.N. 2009. Oceanic, riverine, and genetic influences on spring Chinook salmon migration timing. Ecol. Appl. 19: 1989-2003.

Beacham, T.D., Lapointe, M., Candy, J.R., McIntosh, B., MacConnachie, C., Tabata, A., Kaukinen, K.,

680 Deng, L, Miller, K.M., and Withler, R.E. 2004. Stock identification of Fraser River sockeye salmon using microsatellites and major histocompatibility complex variation. Trans. Am. Fish. Soc. 133:11171137.

Beer, W.N. 2007. Run timing of adult chinook salmon passing Bonneville Dam on the Columbia River,

685 Seattle: Columbia Basin Research, White Paper, University of Washington.

Berdahl, A., Westley, P.A.H., Quinn, T.P. 2017. Social interactions shape the timing of spawning migrations in an anadromous fish. Animal Behav. 126: 221-229.

690 Blackburn, D. 1987. Sea surface temperature and pre-season prediction of return timing in Fraser River sockeye salmon (Oncorhynchus nerka). pp. 296-306 In Smith, H.D., Margolis, L, Wood, C.C. Sockeye salmon (Oncorhynchus nerka) population biology and future management. Can. Spec. Publ. Fish. Aquat. Sci. 96. 486 p.

695 Bonner, S.J.,Schwarz, C.J. 2011. Smoothing population size estimates for time-stratified mark-recapture experiments using Bayesian P-splines. Biometrics 67: 1498-1507.

Burnham, K.P. and Anderson, D.R. 2001. Kullback-Leibler information as a basis for strong inference 
in ecological studies. Wildlife Res. 28: 111-119.

700

Clark, T.D., Furey, N.B., Rechisky, E.L., Gale, M.K., Jeffries, K.M., Porter, A.D., Casselman, M.T., Lotto, A.G., Patterson, D.A., Cooke, S.J., Farrell, A.P., Welch, D.W., Hinch, S.G. 2016. Tracking wild sockeye salmon smolts to the ocean reveals distinct regions of nocturnal movement and high mortality. Ecol. Appl.: 26: 959-978.

705

Clutter, R.I., Whitesel, L.E. 1956. Collection and interpretation of sockeye salmon scales. IPSFC Bull. 9.

Foucher, R.P., Fournier, D.A. 1982. Derivation of Pacific cod age composition using length-frequency 710 analysis. N. Am. J. Fish. Mgmt. 2: 276-284.

Fournier, D.A., Breen, P.A.1983. Estimation of abalone mortality rates with growth analysis. Trans. Am. Fish. Soc. 112: 403-411.

715 Fournier, D., Archibald, C.P. 1982. A general theory for analyzing catch at age data. Can. J. Fish. Aquat. Sci. 39: 1195-1207.

Gilbert, 1913. Age at maturity of the Pacific coast salmon of the genus Oncorhynchus. Fish. Bull. 32: 1-22. + 29 figs.

Hague, M.J. and Patterson, D.A. 2007. Quantifying the sensitivity of Fraser River sockeye salmon (Oncorhynchus nerka) management adjustment models to uncertainties in run 
timing, run shape and run profile. Can. Tech. Rep. Fish. Aquat. Sci. 2776. 55 + vii p. Hasselblad, V. 1966. Estimation of parameters for a mixture of normal distributions. J. Technometrics 725 8: 431-444.

Hodson, S., Quinn, T.P. 2002. The timing of adult sockeye salmon migration into fresh water: adaptations by populations to prevailing thermal regimes. Can. J. Zool. 80: 542-555.

730 MacDonald, P.D.M., Pitcher, T.J. 1979 Age-groups from size-frequency data: a versatile and efficient method of analyzing distribution mixtures. J. Fish. Res. Board Can. 36: 987-1001.

Rao, C.R. 1965. Linear statistical inference and its applications. Wiley, New York, N.Y. 522 p.

735 Mason, J.E. 1965. Salmon of the North Pacific Ocean - Part IV. Coho, chinook and masou salmon in offshore waters. INPFC Bull. 16. 135 p.

McKinnell, S., Curchitser, E., Groot, C., Kaeriyama, M., Myers, K.W. 2012. PICES Advisory Report on the decline of Fraser River sockeye salmon Oncorhynchus nerka (Steller, 1743) in relation to marine 740 ecology. PICES Sci. Rep. 41.

McKinnell, S., Freeland, H.J., Groulx, S. 1999. Assessing the northern diversion of sockeye salmon returning to the Fraser River. Fish. Oceanogr. 8: 104-114.

745 Narum, S.R., Hatch, D., Whiteaker, J. 2007. Genetic stock identification of chinook salmon mixtures at Bonneville Dam. Project report to the Pacific Salmon Commission, Vancouver, Canada. 15 p. 
Nelder, J.A., Mead, R. 1965. A simplex method for function minimization. Computer J. 7: 308-313.

750 Mittertreiner, A., Schnute, J. 1985. Simplex: A manual and software package for easy nonlnear estimation and interpretation in fishery research. Can. Tech. Rep. Fish. Aquat. Sci. 1384. 49 p.

Quinn, T.P. 2005. The behavior and ecology of Pacific salmon and trout. University of Washington Press. 328 p.

755

Rich, W.H. 1942. The salmon runs of the Columbia River in 1938. Fish. Bull. 50: 1-147.

Ryman, N., Utter, F. 1987. Population genetics and fishery management. Seattle: Washington Sea Grant. 420 p.

760

Schnute, J., Fournier, D.A. 1980. A new approach to length-frequency analysis: growth structure. Can. J. Fish. Aquat. Sci. 37: 1337-1351.

Schnute, J., Sibert, J. 1983. The salmon terminal fishery: a practical, comprehensive timing model. 765 Can. J. Fish. Aquat. Sci. 40: 835-853.

Van Hyning, J.M. 1968. Factors affecting the abundance of fall chinook salmon in the Columbia River. Ph.D. Dissertation, University of Washington.

770 Walton, I. 1653. The Compleat Angler or the Contemplative Man's Recreation. London: Richard 


\section{Marriott.}

Woodey, J.C. 1987. In-season management of Fraser River sockeye salmon (Oncorhynchus nerka): meeting multiple objective. pp. 367-374 In Smith, H.D., Margolis, L, Wood, C.C. Sockeye salmon 775 (Oncorhynchus nerka) population biology and future management. Can. Spec. Publ. Fish. Aquat. Sci. 96. $486 \mathrm{p}$. 
Table 1. Akaike Information Criterion value and parameter estimates for pulse model fits to a simulated migration of three co-migrating populations with widely separated peak dates. J indicates the complexity of the model (number of pulses allowed). Parameter symbols are

780 described in the text. The underlined row shows the values of parameters that were used in the simulation to create the observed data. The parameters (enclosed within parentheses) is a ghost peak $(\pi=0 \%)$ that arose from overfitting ( 4 pulses when the data were known to contain only 3 ).

785

$\mathrm{J} \quad \mathrm{AIC}$

\begin{tabular}{rr}
$b$ & $x^{\prime}$ \\
-1.0 & 0.05 \\
\hline
\end{tabular}

$\tau$
110.0

$\pi$
0.25

\begin{tabular}{rr}
$b$ & $x^{\prime}$ \\
-1.0 & 0.05 \\
\hline
\end{tabular}

$\tau$
180.0

$\pi$
0.25

\begin{tabular}{rrrr}
$b$ & $x^{\prime}$ & $\tau$ & $\pi$ \\
-1.0 & 0.05 & 250.0 & 0.50 \\
\hline
\end{tabular}

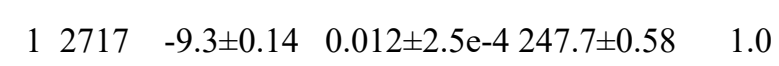

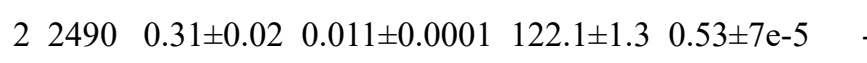

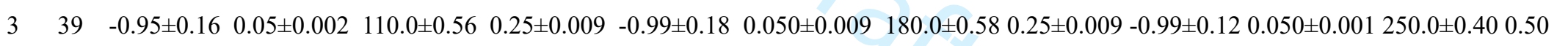

$4 \quad 45 \quad-0.95 \pm 0.16 \quad 0.05 \pm 0.002 \quad 109.9 \pm 0.56 \quad 0.25 \pm 0.01 \quad-1.0 \pm 0.19 \quad 0.050 \pm 0.002 \quad 180.0 \pm 0.58 \quad 0.25 \pm .01 \quad-0.99 \pm 0.12 \quad 0.050 \pm 0.001 \quad 250.0 \pm 0.40 \quad 0.50$ 
Table 2. Parameter and 95\% interval estimates associated with run timing curves of Chilko Lake sockeye salmon smolts (Figure 2). $\mathrm{J}$ is the pulse number. $x^{\prime}, b$ and $\tau$ are described in Equation 1. $\pi$ is the fraction of the total abundance in each pulse; the last of these each year has no interval estimate as it is calculated rather than estimated.

\begin{tabular}{|c|c|c|c|c|c|}
\hline \multirow[t]{4}{*}{800} & Year & $\mathrm{J}$ & Parameter & Est. & C.I. \\
\hline & 1998 & 1 & $b$ & -0.35 & $-1.82-1.14$ \\
\hline & 1998 & 1 & $x^{\prime}$ & 0.26 & $0.09-0.42$ \\
\hline & 1998 & 1 & $\tau$ & 114.6 & $113-116$ \\
\hline & 1998 & 1 & $\pi$ & 0.18 & $0.16-0.20$ \\
\hline \multirow[t]{5}{*}{805} & 1998 & 2 & $b$ & 0.31 & $-0.54-1.15$ \\
\hline & 1998 & 2 & $x^{\prime}$ & 0.23 & $0.06-0.40$ \\
\hline & 1998 & 2 & $\tau$ & 127.8 & $126.5-129.1$ \\
\hline & 1998 & 2 & $\pi$ & 0.62 & $0.58-0.66$ \\
\hline & 1998 & 3 & $b$ & -0.98 & $-11.3-9.3$ \\
\hline \multirow[t]{4}{*}{810} & 1998 & 3 & $x^{\prime}$ & 0.27 & $0.00-0.74$ \\
\hline & 1998 & 3 & $\tau$ & 135.7 & $132.5-138.9$ \\
\hline & 1998 & 3 & $\pi$ & 0.20 & \\
\hline & 1999 & 1 & $b$ & -0.52 & $-1.13-0.09$ \\
\hline
\end{tabular}




\begin{tabular}{|c|c|c|c|c|c|}
\hline & 1999 & 1 & $x^{\prime}$ & 0.17 & $0.13-0.22$ \\
\hline \multirow[t]{5}{*}{815} & 1999 & 1 & $\tau$ & 126.2 & $125.3-127.1$ \\
\hline & 2000 & 1 & $b$ & -0.82 & $-2.9-1.2$ \\
\hline & 2000 & 1 & $x^{\prime}$ & 0.13 & $0.08-0.18$ \\
\hline & 2000 & 1 & $\tau$ & 121.2 & $118.3-124.1$ \\
\hline & 2000 & 1 & $\pi$ & 0.84 & $0.83-0.85$ \\
\hline \multirow[t]{5}{*}{820} & 2000 & 2 & $b$ & 0.04 & $-2.5-2.6$ \\
\hline & 2000 & 2 & $x^{\prime}$ & 0.30 & $0.046-0.55$ \\
\hline & 2000 & 2 & $\tau$ & 136.1 & 133.2-138.9 \\
\hline & 2000 & 2 & $\pi$ & 0.16 & \\
\hline & 2001 & 1 & $b$ & -0.47581 & $-1.54-0.59$ \\
\hline \multirow[t]{5}{*}{825} & 2001 & 1 & $x^{\prime}$ & 0.12 & $0.08-0.17$ \\
\hline & 2001 & 1 & $\tau$ & 121.7 & $119.8-123.5$ \\
\hline & 2001 & 1 & $\pi$ & 0.85 & $0.84-0.85$ \\
\hline & 2001 & 2 & $b$ & -0.02 & $-2.43-2.39$ \\
\hline & 2001 & 2 & $x^{\prime}$ & 0.28 & $0.07-0.49$ \\
\hline \multirow[t]{2}{*}{830} & 2001 & 2 & $\tau$ & 133.1 & $130.7-135.5$ \\
\hline & 2001 & 2 & $\pi$ & 0.15 & \\
\hline
\end{tabular}


Table 3. Average values (1980-2017) and 95\% confidence intervals of parameters estimated from the pulse migration model for large chinook salmon passing Bonneville dam.

$\begin{array}{cccccc}\text { Run } & \begin{array}{c}\text { Abundance } \\ (\mathrm{x} \mathrm{1000)}\end{array} & \text { Skewness } & \text { Compression } & \text { Peak date } & \text { Proportion } \\ \text { Spring } & 103.2 & -0.47 & 0.043 & 115.4 & 0.23 \\ \text { c.i. } & 83.1: 123.4 & -0.69:-0.24 & 0.036: 0.051 & 113.0: 117.6 & 0.20: 0.26 \\ \text { Summer } & 83.9 & -0.39 & 0.015 & 173 & 0.15 \\ \text { c.i } & 61.7: 106.1 & -0.77:-0.01 & 0.014: 0.017 & 169.5: 176.6 & 0.13: 0.17 \\ \text { Fall } & 305.8 & -0.75 & 0.042 & 249.6 & 0.62 \\ \text { c.i. } & 235.0: 376.6 & -1.25:-0.26 & 0.040: 0.045 & 248.6: 250.6 & 0.59: 0.62\end{array}$


Table 4. By year, comparisons of run abundances (numbers of large adult chinook salmon) estimated by the pulse model, by traditional cutoff dates, and by the 2005 fishery management date (June 15) for the Spring/Summer transition.

\begin{tabular}{|c|c|c|c|c|c|c|c|c|c|}
\hline \multirow[t]{2}{*}{840} & \multirow[t]{2}{*}{ Year } & \multicolumn{3}{|c|}{ Spring } & \multicolumn{3}{|c|}{ Summer } & \multicolumn{2}{|c|}{ Fall } \\
\hline & & May 31 & June 15 & Model & May 31 & June 15 & Model & Aug 1 & Model \\
\hline & 1980 & 52874 & 57077 & 55136 & 27003 & 22800 & 32045 & 127893 & 120588 \\
\hline & 1981 & 62827 & 66453 & 64781 & 22363 & 18737 & 27390 & 147109 & 140127 \\
\hline & 1982 & 70011 & 75888 & 71307 & 20129 & 14252 & 26360 & 157771 & 150246 \\
\hline \multirow[t]{5}{*}{845} & 1983 & 54898 & 59891 & 56886 & 18046 & 13053 & 20260 & 112721 & 108519 \\
\hline & 1984 & 46589 & 50310 & 48609 & 22398 & 18677 & 35583 & 147478 & 132273 \\
\hline & 1985 & 83182 & 88932 & 87693 & 24236 & 18486 & 31549 & 189011 & 177187 \\
\hline & 1986 & 118082 & 125759 & 113840 & 26221 & 18544 & 49437 & 226426 & 207453 \\
\hline & 1987 & 98573 & 109039 & 95526 & 33033 & 22567 & 70948 & 337004 & 302137 \\
\hline \multirow[t]{5}{*}{850} & 1988 & 89920 & 98539 & 71926 & 31628 & 23009 & 71263 & 290348 & 268712 \\
\hline & 1989 & 81267 & 87884 & 77780 & 28789 & 22172 & 45046 & 263149 & 250377 \\
\hline & 1990 & 94158 & 100366 & 95203 & 24983 & 18775 & 35411 & 177384 & 165913 \\
\hline & 1991 & 57339 & 61923 & 53379 & 18897 & 14313 & 39445 & 150175 & 133587 \\
\hline & 1992 & 88115 & 93739 & 86276 & 15270 & 9646 & 21206 & 116303 & 112206 \\
\hline 855 & 1993 & 110820 & 118940 & 102353 & 22045 & 13925 & 31172 & 126472 & 125812 \\
\hline
\end{tabular}




\begin{tabular}{|c|c|c|c|c|c|c|c|c|}
\hline 1994 & 20169 & 23160 & 18954 & 17631 & 14640 & 29585 & 170397 & 159659 \\
\hline 1995 & 10192 & 12781 & 8861 & 15030 & 12441 & 21912 & 164197 & 158646 \\
\hline 1996 & 51264 & 55235 & 51057 & 16113 & 12142 & 24191 & 205507 & 197636 \\
\hline 1997 & 114000 & 124252 & 118560 & 27939 & 17687 & 36125 & 218734 & 205988 \\
\hline \multirow[t]{5}{*}{860} & 38342 & 44267 & 36463 & 21433 & 15508 & 25886 & 189085 & 186513 \\
\hline & 38669 & 43023 & 39008 & 26169 & 21815 & 33538 & 242143 & 234435 \\
\hline & 177740 & 185774 & 177621 & 30752 & 22718 & 38705 & 193219 & 185386 \\
\hline & 391367 & 414628 & 344349 & 76156 & 52895 & 156798 & 400205 & 366580 \\
\hline & 269520 & 308887 & 227164 & 127436 & 88069 & 198536 & 474807 & 446064 \\
\hline \multirow[t]{5}{*}{865} & 195770 & 229501 & 177056 & 114808 & 81077 & 168321 & 610736 & 576021 \\
\hline & 168794 & 196428 & 125980 & 93190 & 65556 & 158714 & 584042 & 561375 \\
\hline & 74053 & 97397 & 51829 & 79208 & 55864 & 112311 & 417152 & 406284 \\
\hline & 96458 & 126158 & 161719 & 97519 & 67819 & 47085 & 299731 & 284904 \\
\hline & 66646 & 80829 & 58353 & 47882 & 33699 & 61231 & 161426 & 156367 \\
\hline \multirow[t]{3}{*}{870} & 124370 & 150118 & 125112 & 79191 & 53443 & 87613 & 315381 & 306218 \\
\hline & 114544 & 147489 & 88503 & 81936 & 48991 & 110418 & 283804 & 281372 \\
\hline & 244424 & 277390 & 226898 & 97604 & 64638 & 119794 & 467771 & 463108 \\
\hline 2011 & 167146 & 205431 & 147475 & 108279 & 69994 & 136518 & 401746 & 393180 \\
\hline
\end{tabular}




$\begin{array}{cccccccccccc} & 2012 & 155940 & 183909 & 128270 & 83454 & 55485 & 125527 & 350543 & 336147 \\ 875 & 2013 & 83345 & 112934 & 59805 & 93097 & 63508 & 126636 & 953222 & 943227 \\ & 2014 & 188083 & 224946 & 123955 & 109734 & 72871 & 202485 & 854826 & 826204 \\ & 2015 & 220480 & 265558 & 159409 & 161735 & 116657 & 253488 & 954886 & 924204 \\ & 2016 & 135808 & 168548 & 60969 & 120311 & 87571 & 227291 & 441862 & 409723 \\ & 2017 & 83624 & 107524 & 137583 & 88044 & 64144 & 50971 & 317308 & 300422\end{array}$


Table 5. Goodness of fit statistics for the 2017 large adult chinook salmon migration at Bonneville with models of varying complexity.

Columns indicate the number of pulses in the model, the value of the objective function at the minimum $(A)$, the coefficient of determination, and the Akaike Information Criterion (AIC). The most parsimonious fit (lowest AIC) for 2017 was a model with 5 pulses (bold).

$\begin{array}{rrrrr} & \text { Pulses } & A & \mathrm{r}^{2} & \text { AIC } \\ 885 & 1 & 442.0 & 0.66 & 1303 \\ & 2 & 189.5 & 0.72 & 105 \\ & 3 & 99.8 & 0.76 & 68 \\ & & & & \\ & 4 & 90.8 & 0.78 & 71 \\ & \mathbf{5} & \mathbf{2 6 . 5} & \mathbf{0 . 9 7} & \mathbf{4 5} \\ & 6 & 28.2 & 0.95 & 52 \\ & & & & \\ & 10 & 67.2 & 0.91 & 73\end{array}$


Table 6. Maximum likelihood estimates of the model parameters of each pulse (J) of sockeye salmon CPUE in the Strait of Juan de Fuca gillnet and seine test fisheries in 2014 (Figure 8). Asymptotic confidence intervals (95\%) appear following the \pm symbol. Interval estimates are symmetrical about $\pi^{0.5}$ but asymmetrical for $\pi$ so the back-transformed interval is shown; negative lower bounds are shown as zero.

895 Gillnet

$\mathrm{J} \quad b$

$1 \quad 0.58 \pm 2.7 \quad 0.22 \pm 0.56173 .3 \pm 5$

$2 \quad-0.30 \pm 1.7 \quad 0.09 \pm 0.38 \quad 184.5 \pm 6 . \quad 0.07>0.31<0.55$

$\begin{array}{lllll}3 & 0.06 \pm 9.0 & 0.26 \pm 0.6 & 189.5 \pm 6 & 0>0.14<0.4\end{array}$

$900 \quad 4 \quad 0.42 \pm 1.9 \quad 0.23 \pm 0.28 \quad 198.2 \pm 2.7 \quad 0.17>0.24<0.31$

$\begin{array}{lllll}5 & -2.22 \pm 16 . & 0.19 \pm 0.32 & 210.1 \pm 4.0 & 0.07>0.14<0.21\end{array}$

$\begin{array}{llll}6 & 0.74 \pm 1.9 & 0.19 \pm 0.27 & 215.5 \pm 5.7\end{array}$ 7
Seine

$b \quad x^{\prime} \quad \tau \quad \pi$

$0.94 \pm 0.1 \quad 0.08 \pm 0.01 \quad 207.2 \pm 1.0 \quad 0.390>0.391<0.393$

$-6.9 \pm 4.3 \quad 0.22 \pm 0.05 \quad 218.2 \pm 0.3 \quad 0.238>0.24<0.242$

$\begin{array}{llll}-0.29 \pm 0.2 & 0.22 \pm 0.02 & 232.7 \pm 0.2 & 0.37\end{array}$ 
905
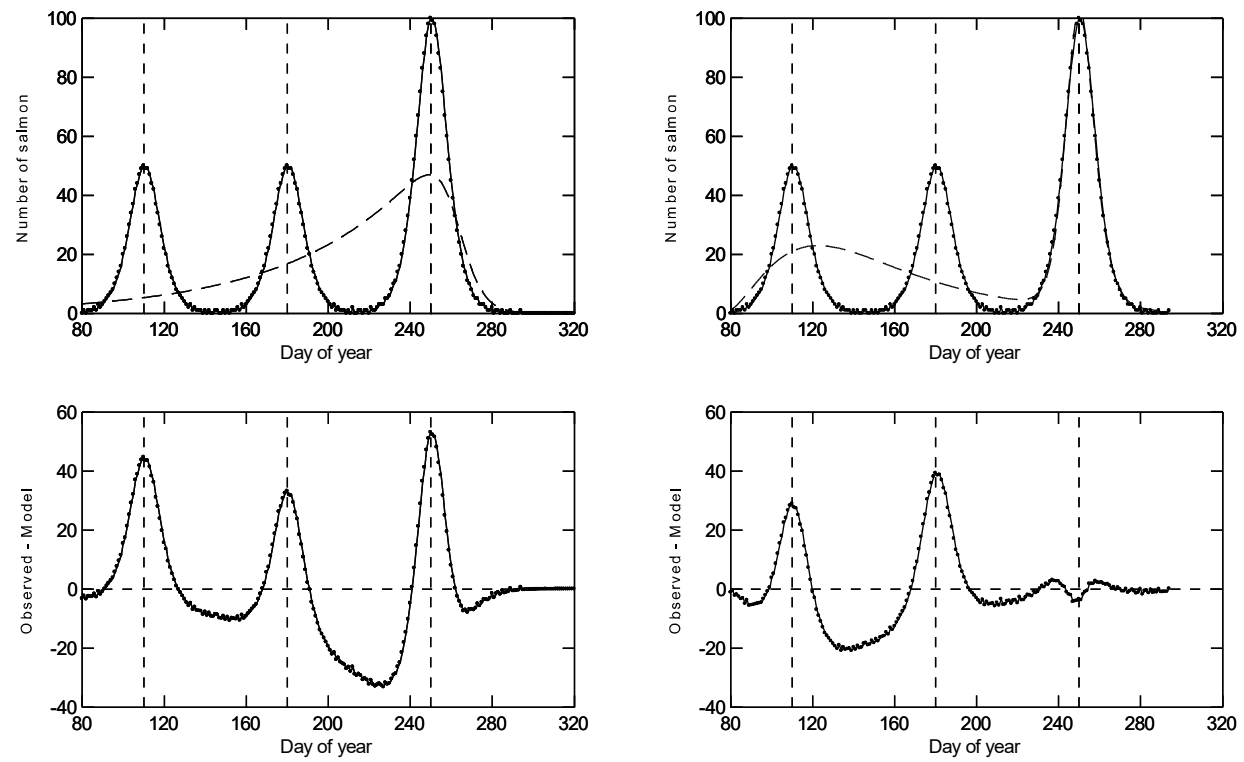

FIGURE 1: [LEFT: SINGLE PULSE MODEL] THE UPPER PANEL SHOWS THE ABUNDANCES OF 3 SIMULATED POPULATIONS FIT TO A SINGLE PULSE MODEL. MODEL ABUNDANCE IS INDICATED BY A DASHED CURVE. THE LOWER PANEL SHOWS THE RESIDUALS (OBSERVED-MODEL) ARISING FROM THE DATA PLOTTED IN THE UPPER PANEL. THE VERTICAL LINES INDICATE THE PEAK DATE OF MIGRATION OF EACH POPULATION. [RIGHT: TWO PULSE MODEL] AS LEFT BUT FOR A TWO PULSE MODEL. NOTE THAT THE LINE OF THE SECOND MODEL PULSE AND THE THIRD OBSERVED PULSE ARE SUPERIMPOSED. THE FITS TO MODELS WITH 3 OR 4 PULSES ARE NOT SHOWN AS THE DATA AND THE MODEL LINES ARE SUPERIMPOSED. 

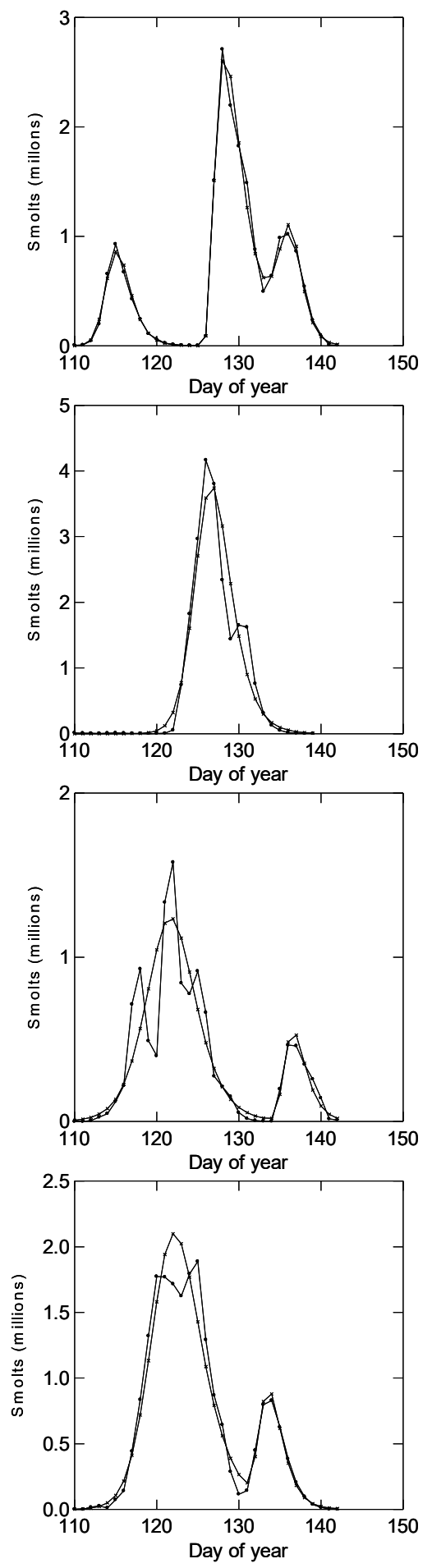

FIGURE 2: NUMBER OF SOCKEYE SALMON SMOLTS (MILLIONS) EMIGRATING FROM CHILKO L. DAILY $(\bullet)$ AND PULSE MODEL FIT $(\times)$ TO THESE DATA (SMOOTHED WITH A 3-DAY RUNNING MEAN). YEARS ARE 1998 [UPPER] TO 2001 [LOWER]. 


\section{0}

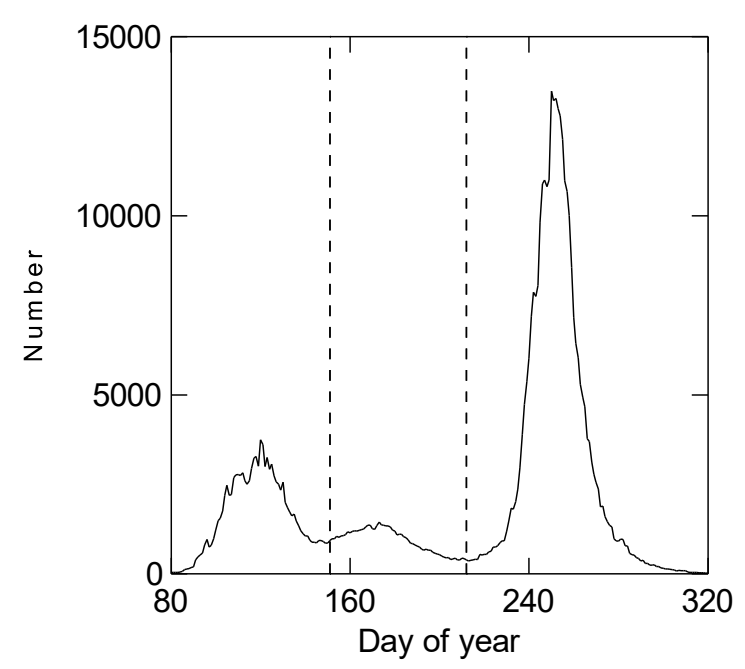

FIGURE 3: AVERAGE DAILY ABUNDANCE OF OF LARGE ADULT CHINOOK SALMON MIGRATING PAST BONNEVILLE DAM, 1980-2017. DASHED VERTICAL LINES INDICATE TRADITIONAL SEPARATION OF SPRING, SUMMER, AND FALL RUNS. 


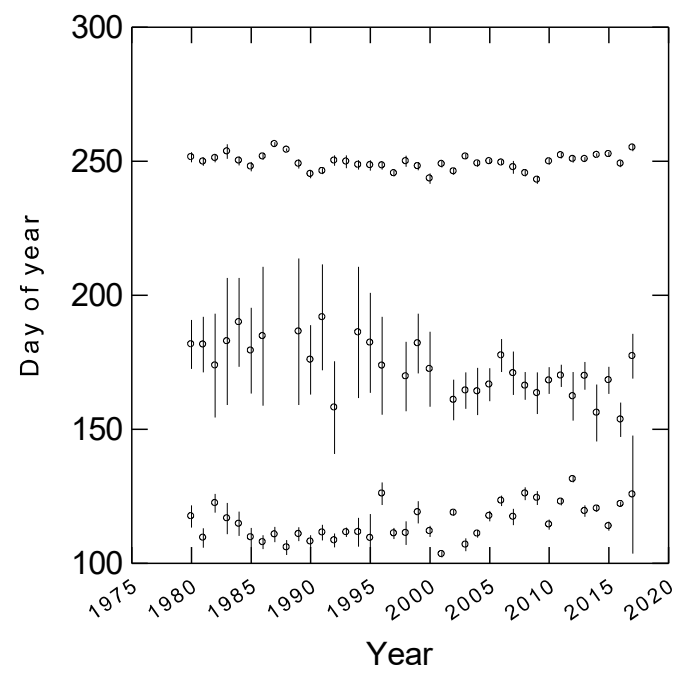

FIGURE 4: ANNUAL ESTIMATES OF PEAK DATE ( $995 \%$ C.I.) FOR SPRING, SUMMER AND FALL RUNS ARISING FROM PULSE MODEL FITS TO LARGE ADULT CHINOOK SALMON COUNTS AT BONNEVILLE DAM FROM 1980 TO 2017. 


\section{Page 49 of $57, \quad$ Canadian Journal of Fisheries and Aquatic Sciences}
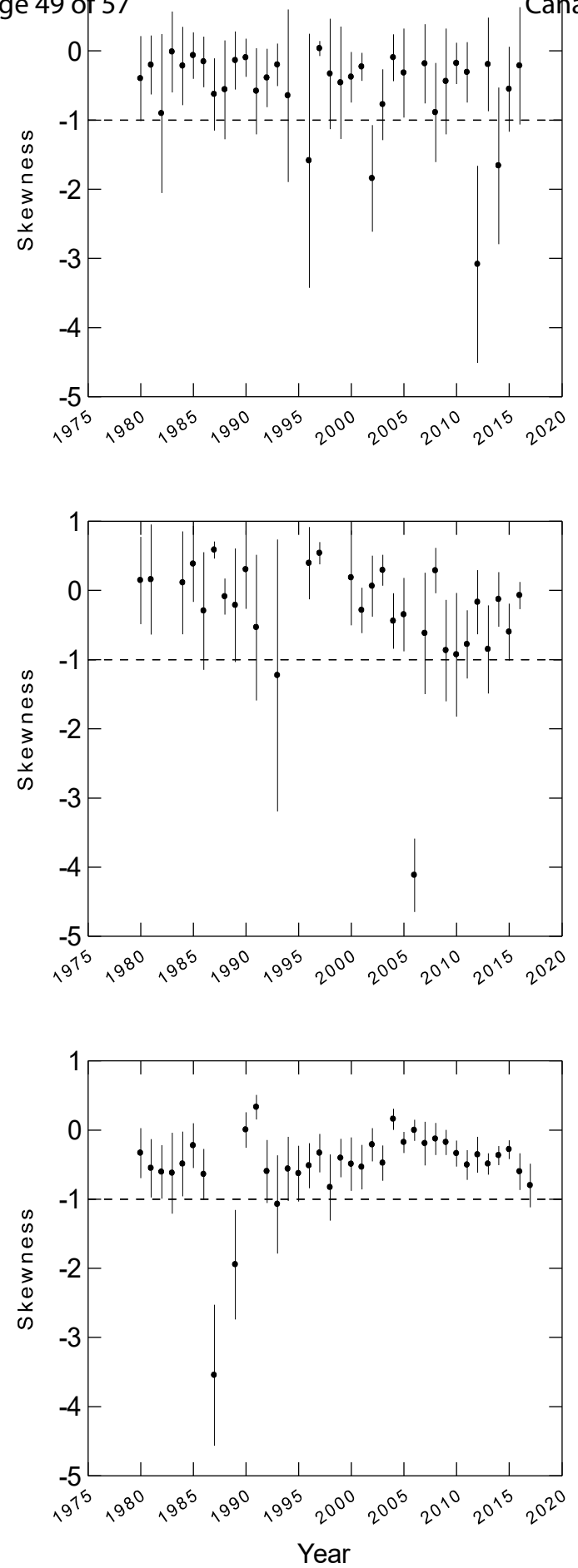

FIGURE 5: ANNUAL ESTIMATES OF SKEWNESS ( $\pm 95 \%$ C.I.) FOR SPRING [TOP PANEL], SUMMER RUN AND FALL RUN [BOTTOM PANEL] ARISING FROM PULSE MODEL FITS TO LARGE ADULT CHINOOK SALMON COUNTS AT BONNEVILLE DAM FROM 1980 TO 2017. THE DASHED HORIZONTAL LINE $b=-1$ INDICATES SYMMETRY. 

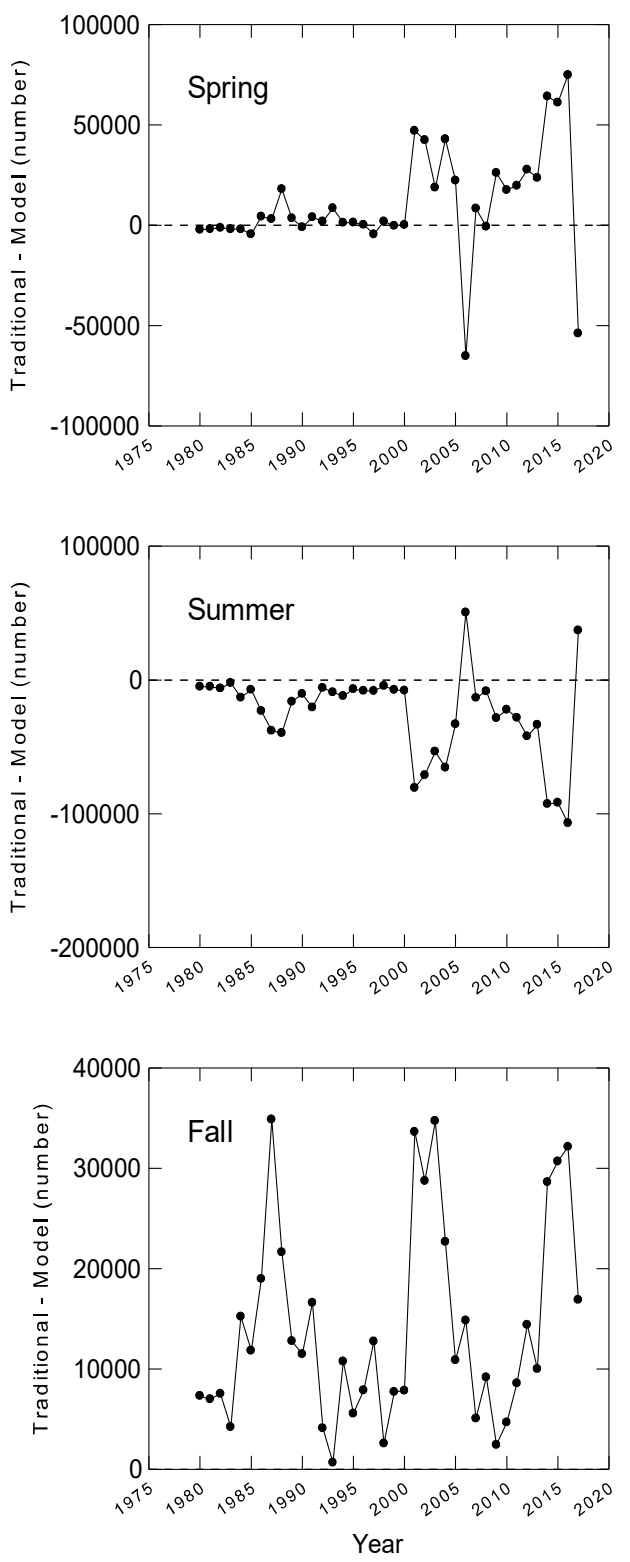

FIGURE 6: ANNUAL DIFFERENCES BETWEEN TRADITIONAL COUNTS AND MODEL ESTIMATES FOR 3 RUNS OF LARGE ADULT CHINOOK SALMON PAST

915 BONNEVILLE DAM, 1980-2017. 


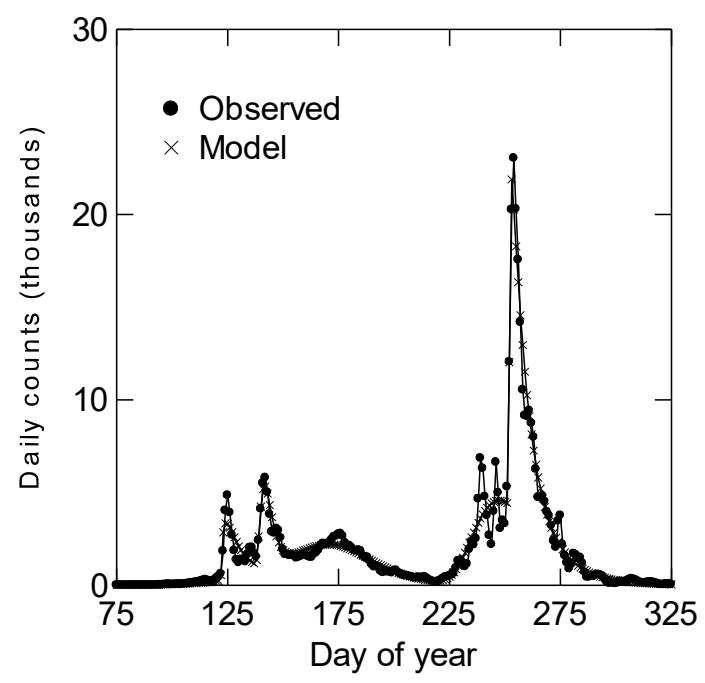

FIGURE 7: OBSERVED NUMBERS OF LARGE ADULT CHINOOK SALMON PASSING BONNEVILLE DAM IN 2017 AND A 5 PULSE MODEL FIT. ESTIMATED PERCENTAGE IN EACH PULSE, FROM EARLIEST TO LATEST IS: $6.1 \%, 6.1 \%$, 23.8\%, 34.4\%, 29.6\%. SUMS WITHIN TRADITIONAL RUNS ARE $12.2 \%$ (SPRING), 23.8\% (SUMMER), 64\% (FALL). 

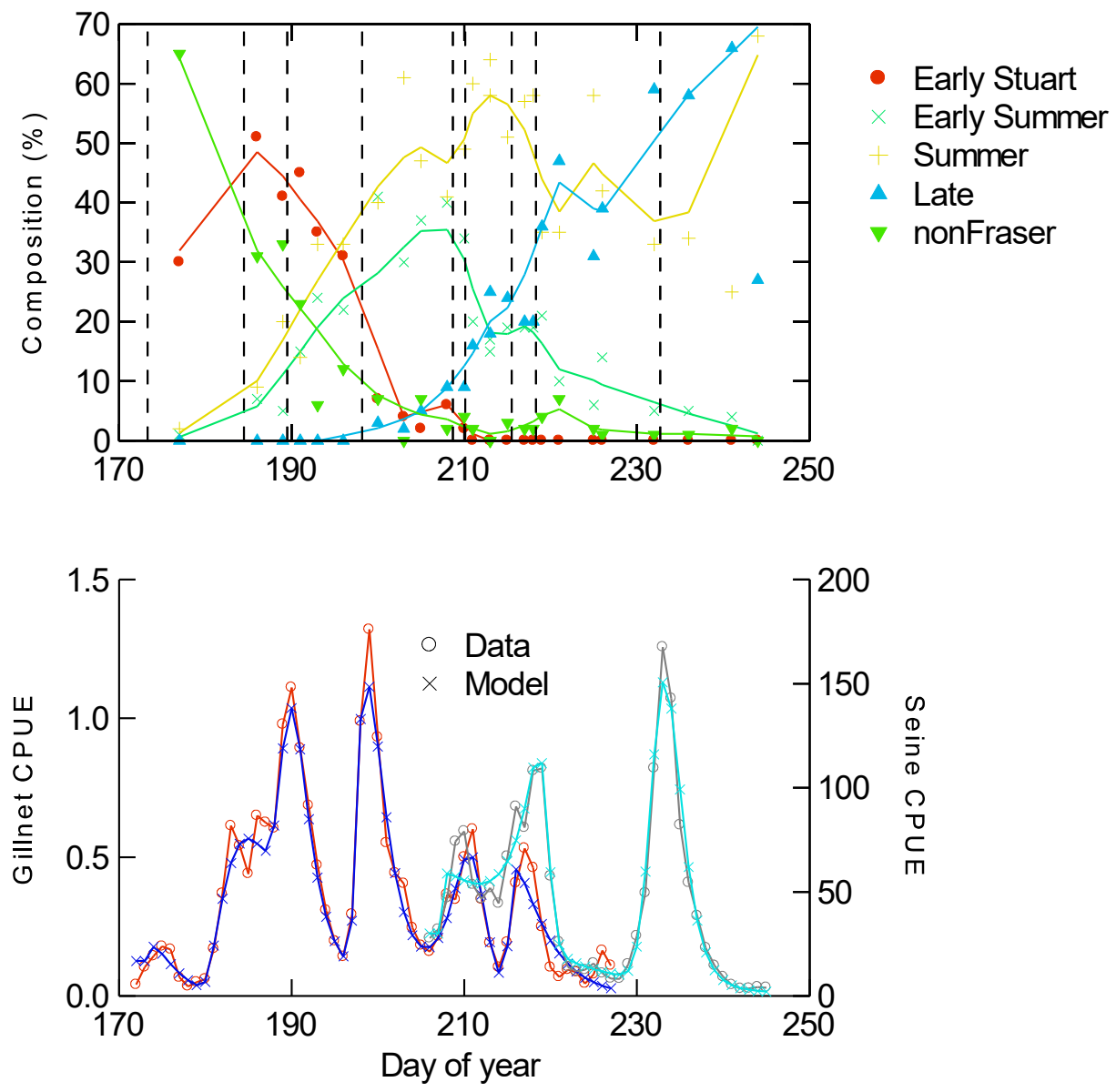

FigURE 8: [BOTTOM PANEL] PULSE MODEL FIT TO DAILY SOCKEYE SALMON CPUE FROM THE JUAN DE FUCA STRAIT GILLNET TEST FISHERY IN 2014 (DATA:RED, MODEL:BLUE), SUPERIMPOSED ON A PULSE MODEL FIT INDEPENDENTLY TO SOCKEYE SALMON CPUE DATA FROM THE JUAN DE FUCA STRAIT SEINE TEST FISHERY (DATA:GREY, MODEL:CYAN). NOTE THAT CPUE SCALES DIFFER BETWEEN FISHERIES. [TOP PANEL] ESTIMATES OF REGIONAL STOCK COMPOSITION WITHIN SAMPLES DETERMINED BY DNA ANALYSIS OF THE TEST FISHERY CATCHES. DASHED VERTICAL LINES INDICATE PEAK DATES ESTIMATED BY THE PULSE MODEL IN THE LOWER PANEL (FROM TABLE 6).TWO PAIRS OF ADJACENT DASHED LINES NEAR DOY 208 AND 215 INDICATE PEAK DATES FOR THE SAME PULSE ESTIMATED BY THE TWO GEAR TYPES. 


\section{Appendix 1. Autodetection of pulses}

This study involved fitting models to more than 40 salmon migration time series so a few practical matters came to the fore. Handled individually, each data set would have consumed a considerable amount of time to examine, determining initial parameter estimates, fit the model, examine the

925 residuals, and repeat as needed. That reality inspired automation of some aspects of the process but particularly the development of initial complexity of the model and the initial parameter estimates. In this regard, it can be desirable to have an objective approach to detecting candidate pulses. One approach that was tried initially was to begin by fitting each time series to the simplest model, a single pulse, then increasing the complexity as needed. While this was a successful approach, it was relatively

930 inefficient especially when the data or prior knowledge indicated clearly that more pulses were present. The approach employed in the present study shifted to one that began by identifying a maximum number of pulses in the data before pruning out the unwanted peaks according to some criteria.

A "candidate" pulse was defined as a transient period of increasing abundance leading to a peak before diminishing. This can occur in as little as three days for a short pulse, but typically such brief

935 increases in abundance are not the focus of study. These ephemeral events tend to be the high frequency components of variability (a.k.a. statistical noise) in the time series that can be controlled to a certain extent by applying a running average. Through trial and error, the following evolved as a generally satisfactory approach to the challenge of finding pulses automatically.

\section{Phase 1 (initial number of pulses)}

1. A pulse can be identified using a $2^{\text {nd }}$ order polynomial (quadratic) fit to "short" sequences of abundance versus time data. The sign of the coefficient on the squared term in the polynomial indicates the direction of curvature; peaks have a negative sign. A quadratic can be fit repeatedly to sequences of three days (the day, the day before and the day after) beginning with 
945 the second day of observations to the second to last day. As the sliding 3-day window passes over a peak date of a pulse, the magnitude of the coefficient (negative) becomes greater before diminishing to a sequence of positive coefficients during a period between pulses. Windows of short duration generally find more candidates than windows of long duration so some experimentation may be required to accommodate the characteristics of a particular time series. If the relative abundances of pulses differ greatly, this phase of analysis can be conducted on $\ln$ $(\mathrm{x}+1)$ transformed data to enhance the smaller pulses and diminish the influence of large pulses.

2. As the direction of quadratic curvature in the abundance time series is measured by only a few days of observations, a potential problem arises when spurious negative coefficients (putative peaks) occur in data that do not reflect extended pulses of migration. An extreme example might be the appearance of a single fish on some day, with no fish on the day prior or day following $(0,1,0)$. The coefficient that arises from this sequence of observations will be negative. At the peak of a pulse, the coefficient of the linear term in the polynomial will tend toward zero, but at least it will be a small value that is either negative or positive. In practice, the ratio of the quadratic coefficient to the absolute value of the linear coefficient proved to be a reasonably reliable pulse detector. If some period in a time series exhibits random high frequency variation, some spurious negative coefficients will be generated. To restrict the incidence of spurious peaks that are not migration pulses, the sequence of daily quadratic coefficients can themselves be smoothed (running mean). While this may not eliminate all spurious peaks during the initial phase of the search, it will reduce their number. In a sequence of negative ratios, typically indicating a pulse, the date of the most extreme of these was used as the initial estimate of the peak date of the pulse. The duration of the sliding quadratic window can be varied with shorter windows generally finding more candidate pulses.

Phase 2 (parameter estimation) 
1. Having determined $\mathrm{N}$, the initial number of pulses, most nonlinear parameter estimation algorithms require initial estimates of all parameters in the model. In practice, setting all $b_{j}=$ -1.0 (symmetry), $x_{j}^{\prime}=0.05$ as the initial estimates of the shape parameters has worked although some alternatives are appropriate when there are substantial differences in the shapes of pulses. For example, the Spring and Fall runs of chinook salmon past Bonneville dam are relatively compressed $\left(x^{\prime}>0.1\right)$ whereas the Summer run is more protracted with a much smaller fraction passing on the peak date (e.g. $\left.x^{\prime}=0.01\right)$. In a year when the Summer run forms an exceptionally small proportion of the total return, there is some benefit to providing better initial estimates as the pulse will often be difficult to detect. Initial estimates of the proportions in each of the first $\mathrm{N}-1$ pulses can be set to $1 / \mathrm{N}$. Experience found that preliminary estimates of $\pi_{\mathrm{j}}$ can be produced in Phase 1 by integrating observed abundances within sequences of days with negative quadratic coefficient ratios. This approach was used in Case Study 1 and Case Study 3.

2. Prominent pulses in a time series provide very good initial estimates of peak dates, $\tau_{\mathrm{j}}$. When fitting the model to the data, there was considerable value in holding these parameters constant during the initial stage of the function minimization process as they will already be near to the maximum likelihood estimates. After a preliminary solution is reached, the peak date parameters can be freed and a global minimum sought.

3. Occasionally, the objective function would have a local minimum where two pulses had the same peak date. This typically occurred when some minor pulse, poorly resolved, was adjacent to a larger well resolved pulse. Two pulses with the same peak date is an undesirable situation because they are totally confounded and the minimizer will make many unnecessary function evaluations without making progress. When convergence to a minimum eventually occurs, or some maximum number of function evaluations allowed is triggered, one of the two confounded pulses can be excised, the parameter space reduced, and the minimization 
continued.

\section{Phase 3 (Diagnostics)}

995 1. Once a global minimum has been reached, a correlation or its square can be computed between the observed and modelled abundances to provide a standardized measure of fit of the model to the data. Parameter uncertainties can be determined from the asymptotic variance-covariance matrix, provided that the Hessian matrix of partial second derivatives can be inverted, which was not always possible. The multidimensional topography of the objective function at its minimum can be complex because some parameters are well determined by the data while others are poorly known. Numerical problems of this ilk did arise, but selecting one of the alternative objective functions enabled calculation of the confidence intervals. If parameters are not well determined, the objective function will be flat near the minimum requiring many iterations to locate; a prerequisite for calculating the confidence intervals.

1005 2. After a putative solution has been reached, unnecessary or unwanted pulses become evident in one of two ways: small proportions allocated to them and-or pulses with nearly identical peak dates. The definition of small in the former can be controlled by the analyst based on knowledge of the population structure in the migration, and some minimum difference $(\delta)$ between peak dates can be set. If one of these conditions has occurred, the spurious pulses can be removed automatically from the model and the estimation process is restarted in the reduced parameter space. The initial estimates in the reduced parameter space are those estimated in the previous step. If more than one spurious pulse is detected, all should be removed before restarting the search. Removing one pulse reduces the number of parameters by four.

3. Poorly fitting models generally produced a time series of residuals that oscillate (high autocorrelation) with persistent periods of negative residuals followed by persistent periods of positive residuals. The latter is an indication that more fish have been observed at some than 
were predicted by the number of pulses in the model. These are potential pulses of migration that warrant increasing the complexity of the model. Indeed, there may be several pulses in the residual time series suggesting that greater complexity is required to fit the data.

1020 4. Some attention must be paid to degrees of freedom, which are determined by the duration of the migration and the complexity of the model. With up to four parameters required to describe each pulse, a model of 10 pulses for example, cannot be meaningfully fit to a migration of 30 days because each pulse requires some initial abundance, an increasing period, a peak and a declining period. Three days observing a pulse cannot be expected to generate meaningful estimates of the shape parameters just as two observations might define a straight line but little can be inferred from it. Case Study 2 involved several months of migration observations but only three pulses, providing more precise estimates of the shape parameters than Case Study 1 where there were up to three pulses in one month. 